ROBERT W. STA IGER

University of Wisconsin and

National Bureau of Economic Research

FRANK A. WOLAK

Stanford University and

National Bureau of Economic Research

\title{
Measuring Industry-Specific Protection: Antidumping in the United States
}

Do ANTIDUMPING LAWS have anticompetitive consequences and restrict trade?' These questions arise repeatedly in multilateral and bilateral trade talks. Although there are reasons to suspect that antidumping laws do have such effects, little is known about the size of these effects in practice, and even less about the mechanisms by which they occur. This paper provides estimates of the trade impacts of U.S. antidumping law and the determinants of suit-filing activity from 1980 to 1985 .

Several researchers have challenged the view that antidumping law restricts trade flows only when antidumping duties are actually imposed. These researchers argue that the threat, sometimes even the mere possibility, of duties can also restrict trade. We study three possible channels through which these indirect effects may arise, which we believe, when

We gratefully acknowledge the research assistance provided by Phil Levy, Paul Liu, and Kerry Pannell, as well as financial support from the National Science Foundation. We are also grateful to Azita Amjadi for providing us with access to her compilation of data on antidumping petitions, and to Michael Katz, Leonard Waverman, and Robert Litan for insightful discussant comments. The paper also benefited from the comments of seminar participants at the universities of Wisconsin, Toronto, and Chicago. Finally, we thank Peter Reiss, John Pencavel, and Cliff Winston for extremely detailed and helpful comments on a previous draft. We are responsible for any remaining errors.

1. Dumped imports are defined under U.S. law to be foreign products exported to the U.S. market at prices below "fair value," that is, either below the prices of comparable products for sale in the domestic market of the exporting country or below costs of production. 
combined with the direct effects of duties, capture most of the trade effects of antidumping law. ${ }^{2}$ We refer to these three nonduty effects as the investigation effect, the suspension effect, and the withdrawal effect. Investigation effects occur when an antidumping investigation takes place; suspension effects occur under so-called suspension agreements (when an investigation is suspended in exchange for a promise by foreign firms to stop dumping); and withdrawal effects occur after a petition is simply withdrawn without a final determination.

Our empirical analysis gauges the effect of antidumping petitions by measuring the response of imports and domestic output to the filing and resolution of suits. We use data on the timing and outcome of every antidumping investigation that covered a manufactured product in the United States during the 1980-85 period. This period was chosen because U.S. antidumping law was altered substantially in the Trade Agreements Act of 1979. Our empirical analysis makes three contributions to the existing literature. First, we identify separate trade effects for each phase of the antidumping investigation process and distinguish among an exhaustive list of postinvestigation outcomes. Second, we address aggregation issues that arise in assessing the impact of investigations covering multiple product categories. Third, we jointly estimate filing, import, and output equations that allow for the joint determination of the decision to file, the level of imports, and domestic output. ${ }^{3}$

Our focus on the broader trade effects of antidumping law allows us to consider the possibility that firms in our sample pursue two distinct filing strategies. In modeling the determinants of suit-filing activity, we allow for the coexistence of "outcome filers" and "process filers." Outcome

2. The empirical literature concerned with the determinants and impacts of antidumping petitions is growing. See, for example, Finger (1981), Herander and Schwartz (1984), Salvatore (1987), Hartigan, Kamma, and Perry (1989), Messerlin (1989, 1990), Lichtenberg and Tan (1990), Harrison (1991), and Prusa (1991).

3. The two papers closest in spirit to our work are Lichtenberg and Tan (1990) and Harrison (1991). Lichtenberg and Tan estimate filing, import, and output equations but do not allow for their joint determination. Moreover, they abstract from investigation effects entirely, focusing instead on the implications of different postinvestigation outcomes for import and output levels. Harrison estimates import price equations with a focus on investigation and duty effects, but abstracts from the filing decision entirely. Neither paper makes an attempt to distinguish among the various phases of the investigation process, nor does either paper attempt to account exhaustively for the various postinvestigation outcomes. Finally, neither paper attempts to account for the multiplicity of product-level filings and duties that may arise in a given industry-year observation. 
filers are firms that appear to be motivated by the expectation that they can secure a finding of dumping. Process filers file petitions largely for the trade-restricting effects generated by the investigation process alone.

Our results suggest that two of the three nonduty effects of antidumping law are quite substantial. First, suspension agreements lead to restricted import flows and expanded output from import-competing domestic firms, and these effects are similar in magnitude to the effects of antidumping duties in our sample. Second, investigation effects are substantial, reducing total imports during the period of investigation by roughly half the reduction that would be expected if duties were imposed from the start of the investigation. We do not find statistically significant evidence of a withdrawal effect.

Not surprisingly, our results confirm that, for most industries, the prospect of a dumping finding is an important ingredient in the decision to file and thus that outcome filers are the predominant users of antidumping law. In particular, we find for most industries in our sample that evidence of injury (which is required for a dumping finding) is an important predictor of filing activity by firms. We also find evidence, however, of filing activity that appears to be driven largely by a desire to secure the traderestricting effects generated by the investigation process itself. This latter result, coupled with the finding of a substantial investigation effect, is evidence, we believe, that some firms pursue the process-filing strategy and therefore initiate antidumping procedures for the investigation effects alone.

\section{U.S. Antidumping Law}

We begin by summarizing the steps involved in a U.S. dumping investigation, from initiating the investigation to the final determination and assessment of duties. ${ }^{4}$ This description motivates our empirical specifications below.

Before describing the actual investigation procedure, we make several preliminary observations. First, two findings are necessary for a

4. The Trade Agreements Act of 1979 involved a major rewriting of U.S. antidumping laws. The Trade and Tariff Act of 1984 contains several amendments to the antidumping law of the 1979 Act that, while substantive, are not relevant for the particular issues we consider here. 


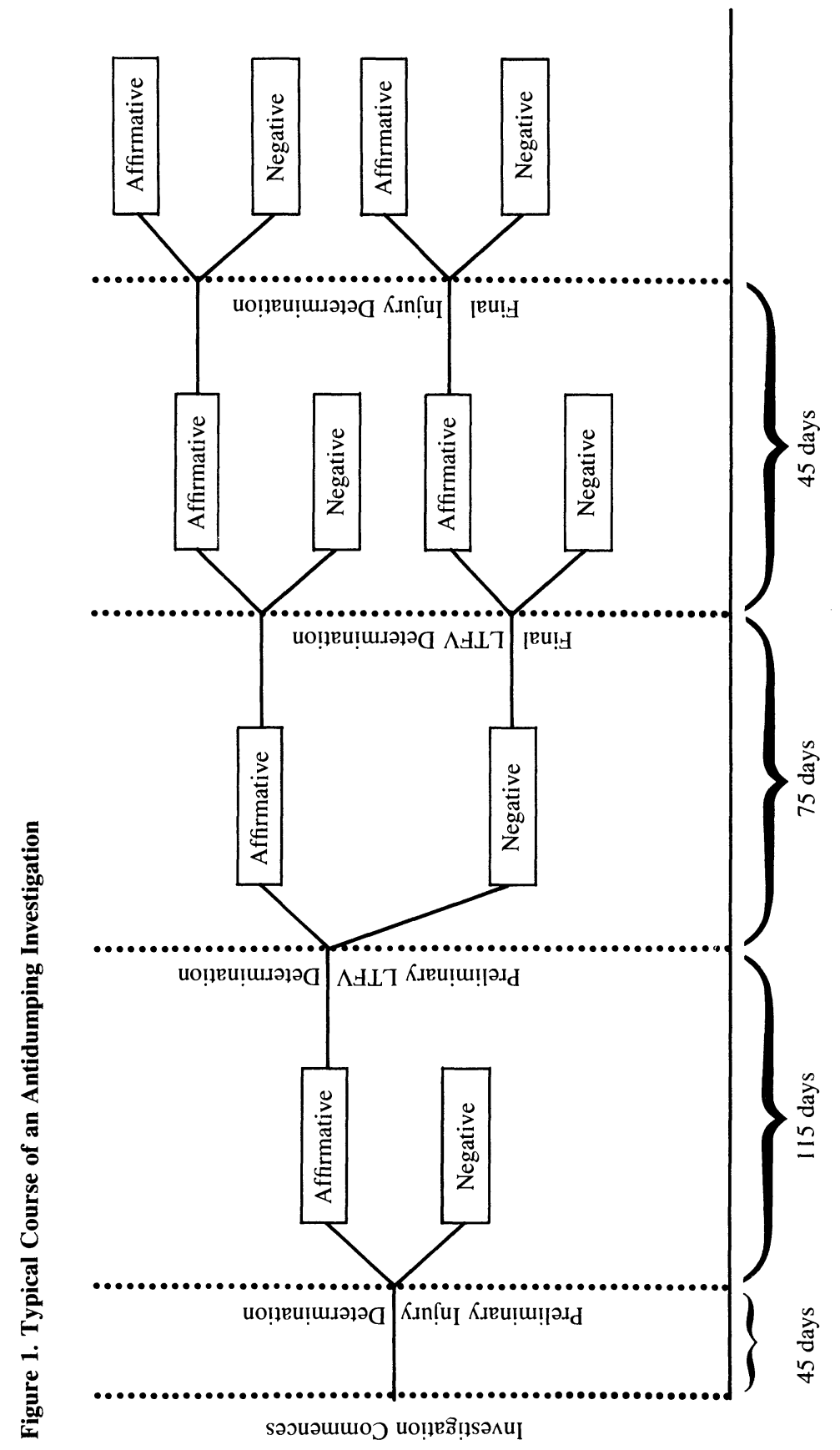


determination of dumping under U.S. law: sales of imports at less than fair value (LTFV), and material injury to the domestic industry because of these imports. The International Trade Commission (ITC) determines whether the domestic industry has been injured, and the Commerce Department's International Trade Administration (ITA) makes the LTFV determination. Each agency makes both a preliminary and a final decision. The statutory time allotted for the entire investigation ranges from ten months to fourteen months under special circumstances. Figure 1 summarizes the timing of the various stages of the suit resolution process.

\section{Investigation Procedure}

Once an antidumping petition is filed, the ITA has 20 days to determine whether the petition is in order and, if so, to commence an investigation. ${ }^{5}$

ITC Preliminary InJury Determination. If the petition determination is affirmative, the ITC has 45 days to make a preliminary determination whether the imports under investigation have "materially injured" the domestic industry, "threatened" it with material injury, or " "materially retarded" the establishment of the industry. If the ITC's preliminary determination is negative, the investigation is terminated, as figure 1 indicates. If this determination is affirmative, as it was for 86 percent of the products investigated during our sample period, then the investigation will run its course unless the petitioner takes action to terminate or suspend the case.

ita Preliminary LTFV Determination. Provided the ITC's preliminary determination is affirmative, and within 160 days of the initial filing of the suit (or 90 days if all interested parties agree to a "waiver of verification'), the ITA must make a preliminary determination whether there is reasonable evidence that the imported merchandise "is being sold, or is likely to be sold, at less than fair value." ${ }^{\prime 6}$ A negative preliminary determination by the ITA does not terminate the investigation, but if the determination is affirmative, as it was for 93 percent

5. Petitions can be either initiated by an "interested party" on behalf of the industry or, on rare occasion, "self-initiated" by the ITA.

6. In "extraordinarily complicated"' cases, the ITA may postpone making its preliminary determination until the 210 th day after filing. 
of the products whose investigations made it past the preliminary injury determination during the 1980-85 period, then the ITA must estimate the "dumping margin," order the "suspension of liquidation" of the affected imported goods, and require the importers to post a cash deposit or bond to cover the estimated dumping duties payable, pending the final outcome of the investigation.

At any point after the ITA's preliminary determination and before the ITC's final determination, the investigation may be terminated or suspended. Termination occurs only if the petition is withdrawn by the petitioner, an action that was taken on 42 percent of the products whose investigations made it past the preliminary injury determination during the 1980-85 period; a large portion of these were in the steel industry. Termination usually results from price agreements reached by the domestic industry and foreign firms named in the suit. ${ }^{7}$ Suspension occurs if the foreign firms reach an agreement with the ITA to stop the LTFV sales to the U.S. market, cease exporting to the U.S. market completely, or, under " extraordinary circumstances," eliminate the "injurious effect" of their actions, including any margin of "underselling", (that is, undercutting the price of the domestic product), without necessarily raising prices so high as to eliminate the full margin of dumping. Such agreements were negotiated for 2 percent of the products whose investigations made it past the preliminary injury determination during the 1980-85 period. Any violation of the suspension agreement automatically renews the investigation.

ITA FinAl LTFV Determination. If the case is neither terminated nor suspended, then the ITA must within 75 days of its preliminary determination make a final determination whether the merchandise under investigation "is being, or is likely to be" sold in the United States at less than fair value. ${ }^{8}$

7. Agreements between foreign firms and domestic petitioners are permitted under the Noerr-Pennington doctrine, which exempts such parties from prosecution under U.S. antitrust law. Direct conversations between domestic and foreign firms concerning prices or quantities would not be protected, however. Consequently, settlements are typically negotiated through the Commerce Department (letter from Gary Horlick, O'Melveny and Myers, Washington, D.C., 1989). See Prusa (1992) for a thorough analysis of this exemption and its implications for the effects of antidumping law.

8. The ITA may postpone its final determination until the 135 th day after its preliminary determination if requested to do so by either the petitioner or the firms against which the dumping allegations were made. 
ITC FINAL InJURy DETERMinAtion. If the ITA's preliminary and final determinations were affirmative, then the ITC must make its final determination of injury within 45 days of the ITA's final determination (or within 120 days of the ITA's preliminary determination, whichever is later). If the ITA's preliminary determination was negative, then the ITC has 75 days from the ITA's affirmative final determination to make its final determination of injury. If the ITC's final determination is also affirmative, the ITA has 7 days within which to instruct customs officers to assess the appropriate antidumping duties. Assessment of dumping duties occurred for 35 percent of the products whose investigations made it past the preliminary injury determination during the 1980-85 period. If either the ITC or the ITA final determination is negative, the investigation is terminated, an outcome which occurred for 21 percent of the products whose investigations made it past the preliminary injury determination over the 1980-85 period.

AsSESSMENT OF ANTIDUMPING Duties. When the final determinations of injury and LTFV sales are both positive, the "definitive" dumping margins for purposes of assessing antidumping duties must be calculated. These calculations are based on the prices of the imports to which they will apply (as opposed to the margins calculated for the LTFV determination, which are based on a sample of imports over a historic period, which typically covers the six months preceding the initiation of the petition). The final assessment of antidumping duties applies retroactively only if the preliminary LTFV determination was affirmative. In this case, antidumping duties would normally be assessed on the relevant imports from the date of the preliminary LTFV determination forward. If the industry alleges "critical circumstances," however, and the ITA and ITC find evidence both that "massive" imports over a "relatively short period" caused material injury and that there is either a history of dumping in the industry or that the importers knew or should have known about ongoing dumping, the dumping duties can be applied retroactively to goods imported ninety days before the preliminary LTFV finding. ${ }^{9}$

In effect, then, antidumping duties may apply to three possible ranges of imports once an affirmative final determination is made. If the preliminary LTFV determination was negative, duties equal to the

9. In practice, however, the conditions for critical circumstances are rarely met. 
actual dumping margins will be imposed on the relevant imports entering the United States on or after the date of final determination. If, alternatively, the preliminary LTFV determination was affirmative, antidumping duties reflecting actual dumping margins will be imposed on imports entering the United States on or after the date of the preliminary LTFV determination, or, in critical circumstances, ninety days before the date of the preliminary LTFV determination.

We now describe the investigation, suspension, and withdrawal effects as well as two distinct filing strategies associated with antidumping petitions. We also develop the research hypotheses that guide our empirical investigation. ${ }^{10}$

\section{Investigation Effects}

Dale discusses two possible reasons for the existence of investigation effects. ${ }^{11}$ The first focuses on the pricing behavior of exporters. As discussed above, in cases where the final injury and dumping determinations are positive and where the preliminary LTFV determination was also affirmative, duties are typically imposed retroactively on imports that enter the United States after the date of the preliminary LTFV finding. The "definitive" margin on which these duties are based is recalculated to reflect the actual dumping margins for imports entering after this date. Thus, an exporter who receives an affirmative preliminary LTFV determination and expects the final determination also to be affirmative can nonetheless reduce antidumping duties, or even avoid them altogether, by raising its price on goods exported after the preliminary LTFV determination date. Under these circumstances, we would expect an affirmative preliminary LTFV finding to lead to a sharp drop in the rate of imports and to a rise in prices, with these effects lasting for the remainder of the investigation. We would also expect the rate of imports, in anticipation of its future fall, to rise somewhat with the filing of a petition. ${ }^{12}$ A second explanation focuses on the importers of

10. Several papers, for example, Prusa (forthcoming), Anderson (1992), and Staiger and Wolak (1992a), have suggested that, in addition to these three nonduty effects, the mere existence of antidumping law can have trade effects even when no petition is filed. We do not attempt to capture such effects in our empirical work.

11. Dale (1980, pp. 85-86).

12. A sufficiently large increase in the flow of imports between the date a petition is filed and the date of a preliminary LTFV determination could, however, trigger the 
the products under investigation. U.S. law imposes the antidumping duties on the importer rather than on foreign exporters, which means that an affirmative preliminary LTFV finding places the importer at considerable risk for future duty payments on any imports purchased after that date. ${ }^{13}$ Again, this situation suggests that an affirmative preliminary LTFV finding, coupled with an expectation that the final determination will also be affirmative, would lead to a sharp drop in the rate of imports and to a rise in prices, with these effects lasting for the remainder of the investigation. ${ }^{14}$ Again, the rate of imports might, if anything, rise when a petition is filed in anticipation of its future fall.

A third alternative to these two interpretations is that domestic firms use the antidumping investigation of foreign firms to dampen competition when costly price wars might otherwise erupt. ${ }^{15} \mathrm{~A}$ formal treatment of the anticompetitive effects of these investigations centers on four features of antidumping law. First, the preliminary finding of injury, which is both necessary and sufficient to ensure that the investigation will run its course (approximately a year) unless the petitioner chooses to stop it, is relatively easy to secure because, at this preliminary stage of the investigation, the ITC typically relies on information

\footnotetext{
"critical circumstances", provisions of U.S. antidumping law, which allow duties to be imposed retroactively to the date of filing.
}

13. Exporters are allowed to reimburse importers for duty payments only if the agreement to purchase was made before the preliminary LTFV determination and only for the products that are exported before the final dumping determination (Dale, 1980, p. 105).

14. Anecdotal support for the trade-restricting effects of preliminary dumping findings is common. For example, in reference to a U.S. antidumping petition brought by the National Knitwear \& Sportswear Association against sweater producers in Hong Kong, South Korea, and Taiwan, the New York Times observed: "The [preliminary dumping] margins were announced as retailers are about to place orders for delivery next fall. Some industry officials said prospects of higher prices, or just the uncertainty over what the new price levels would be, could cause some retailers to switch to domestic suppliers.' See “Imported Sweaters Face Duty,'’ New York Times, April 24, 1990, p. C1.

15. See Staiger and Wolak $(1991,1992 b$, and 1994). The use of antidumping law as a tool to avoid price wars with foreign rivals has been explicitly documented in at least one instance. In January 1938 the South African Iron and Steel Corporation filed an antidumping petition against steel producers in the United States for selling steel in the South African market at prices below those agreed upon by the International Steel Cartel. Dumping duties were levied, and the cartel's pricing arrangements restored (Hexner, 1943). Less direct evidence of firms' turning to antidumping law to avert price wars is provided by Messerlin (1990) for the European Community chemical industry. 
provided by the petitioner. Second, price cutting during the investigation by foreign firms named in the petition will raise the likelihood of an affirmative dumping determination. Third, the prospect of antidumping duties on foreign firms that cut prices during the investigation will give these firms an incentive to keep their prices high. Fourth, this competition-dampening investigation effect is secured only by filing the antidumping petition. ${ }^{16}$ Under these four points, we have argued that the filing of an antidumping petition can dampen competition and lead to greater market share for domestic firms - and in fact to a fall in imports and a rise in domestic output-during the entire period of investigation. ${ }^{17}$ These investigation effects occur because, by filing an antidumping petition, the domestic industry is able to diminish the incentives of foreign firms to pursue domestic market share aggressively while the investigation is proceeding. And with aggressive pricing policies relatively less attractive for foreign firms, higher domestic prices (and lower imports) can be maintained even as domestic firms increase output.

\section{Suspension and Withdrawal Effects}

Imposing antidumping duties is not the only way that antidumping proceedings can have a lasting effect on postinvestigation import flows. Suspension agreements, negotiated between the ITA and foreign firms named in the antidumping petition, are clearly meant to have lasting impacts on import prices and volumes, and they are monitored and enforced by the ITA to ensure that they do have such effects. Because a suspension agreement is intended to stop the dumping in question, it would be surprising if a "suspension effect" did not appear in the data.

16. Of these four points, the second is the least self-evident and requires some elaboration. A crucial step in the ITC's injury determination is establishing a causal link between dumped imports and injury to the domestic industry. Here, the ITC relies heavily on evidence of "underselling," that is, sales of the imported good in the domestic market at a price below that of the domestically produced "like product," and of a relationship between such underselling and increases in foreign market share. Moreover, in its final determination of injury, the ITC routinely considers data on prices and imports from the investigation period. Thus, were a foreign firm to cut its price to steal market share in the domestic market during the investigation, the likelihood would increase that the ITC would find that this increased foreign market share is attributable to "underselling.", That would consequently raise the likelihood of a final determination of injury and the prospect of antidumping duties.

17. Staiger and Wolak (1991). 
A prominent example involving such a suspension agreement was the 1986 U.S.-Japan Semiconductor Trade Arrangement.

Conversely, one might be surprised to see lasting effects from a withdrawn antidumping petition. When a petition is withdrawn, the investigation is terminated, and it might seem a priori that import flows would continue at (or return to) the levels they held before the investigation began, just as in a negative determination. Prusa has provided a bargaining model that overturns this a priori view. ${ }^{18}$ According to Prusa, the antidumping investigation process provides the domestic firms with both a threat of antidumping duties against their foreign rivals as well as cover from domestic antitrust laws under the NoerrPennington doctrine, and this allows them to coordinate on a more trade-restrictive arrangement with foreign firms. ${ }^{19}$ That agreement is then implemented upon the withdrawal of the antidumping petition by the domestic firms. Prusa's model implies that a withdrawn petition could have lasting effects on imports if the investigation process allows foreign and domestic firms to coordinate output or prices in subsequent periods.

\section{Filing Strategies}

It would be natural to think of filing activity as reflecting the desire to secure a finding of dumping and the explicit remedies under the law that such a finding would bring forth, that is, antidumping duties or a suspension agreement in lieu of duties. We call firms that pursue such a filing strategy "'outcome filers."' The potential for investigation and withdrawal effects, however, leads to the possibility of another filing strategy: firms might knowingly file "meritless" antidumping petitions just to trigger the process that leads to these latter effects. We call firms that pursue this second strategy " process filers." For the process-filing strategy to make sense, two logical conditions must hold. First, the antidumping investigation process itself must be obtainable even when a full investigation would not be warranted on the merits of the case. Second, the significant possibility of a dumping finding cannot be a prerequisite for the sought-after investigation or withdrawal effects.

Because the investigation process is secured once an affirmative

18. Prusa (1992).

19. See note 7. 
preliminary injury determination is made, the first condition above is likely to be met. The strict forty-five-day time limit within which the ITC must make this determination forces the ITC to rely heavily at this stage of the investigation on information provided by petitioners. Thus, firms that want the antidumping investigation process should find it relatively easy to obtain, regardless of the merits of their dumping claims.

What the process itself is worth when the case against foreign firms is weak is less clear, however. Dale's two interpretations of the investigation effect imply that petitions which were known by the industry to have little chance of resulting in retroactive dumping duties would be unlikely to have strong trade-restricting effects associated with the investigation process. In contrast, the significant possibility of a dumping finding and retroactive duties is not a prerequisite for the investigation effects under the third interpretation offered above. This is because the investigation effect under this third interpretation comes in the form of a threat to "punish" foreign firms with an antidumping duty if they should "misbehave" and compete too aggressively during the investigation period. Such a threat is made credible by filing the petition; because it is credible, the threatened duties need never be implemented. Thus, under this interpretation, domestic firms may value the price-competition-dampening effects of antidumping investigations for their own sake. These firms may therefore file antidumping petitions with no expectation that they would actually result in duties or other remedies, but only to ensure that the foreign firms do not engage in aggressive pricing behavior during the investigation phase. Nor is the significant probability of a dumping finding necessarily a prerequisite for the withdrawal effect, if domestic firms value Noerr-Pennington exemption from antitrust sufficiently for its own sake.

We will therefore consider the possibility of both outcome and process filers in our empirical work. Outcome filers initiate antidumping petitions when their chances of securing a dumping determination are sufficiently strong. The investigation effect associated with such filers should correspond to the first two interpretations depicted above: the flow of imports should rise upon filing and fall at the point of an affirmative preliminary LTFV determination, remaining low until the conclusion of the investigation. Process filers initiate antidumping petitions without regard to their chances of securing a dumping determi- 
nation, but rather when the risks of competitive price wars are sufficiently severe. In an earlier paper, we argued that firms use the processfiling strategy when capacity utilization falls below a critical level, and thus we will consider the role of capacity utilization as a predictor of the filing activity of process filers ${ }^{20}$ The investigation effects associated with process filers should correspond to the third interpretation depicted above: the flow of imports should fall upon filing and remain low until the conclusion of the investigation. Finally, the withdrawal effect could be associated with either filing strategy, with no a priori difference across outcome or process filers.

\section{The Effects of Antidumping Duties Alone}

We begin our empirical investigation by focusing on the duty effects alone. This is a natural starting point for assessing the impacts of antidumping law, and these findings will provide a benchmark for results of the broader investigation that follows.

First, however, we must describe the data sources and the econometric framework used to measure these impacts. Finally, we present an industry-level model of product-level antidumping-suit filings and estimates of the import-restricting and output-promoting effects that occur from imposing antidumping duties.

\section{Data Sources}

The source for the industry-level economic magnitudes is the Trade Data File compiled by the National Bureau of Economic Research. ${ }^{21}$ This data set contains information on domestic shipments, imports, and exports for 450 U.S. manufacturing industries by four-digit 1972 Standard Industry Code (SIC) from 1958 to 1985 . It also contains information on various economic aggregates by industry such as the level of employment and the size of the capital stock, as well as an industrylevel output price deflator. We use this price deflator to convert all nominal dollar magnitudes to 1972 dollars.

The filing dates for all antidumping suits and the dates for the sub-

20. Staiger and Wolak (1991).

21. Abowd (1990) gives a detailed description of this data set. 
sequent stages of the suit resolution process come from the "Trade Action Monitoring System (TAMS) Pending Investigation Report,', produced monthly by the National Technical Information Service in the Department of Commerce. It tracks all petitions filed under the 1974 Trade Act, listing every month the current status of each petition until its final determination. In addition the ITC links the allegedly dumped products to Tariff Schedules of the United States (TSUS) product codes, and these codes are recorded in the TAMS data set. We explicitly account for filing at the TSUS product code level in our model of filings, imports, and domestic output.

Because the industry-level data are available at the four-digit 1972 SIC level, we must match the TSUS codes to the SIC codes. Using the year-by-year concordance from the "Imports Extract Master Concordance,', produced by the Commerce Department's Foreign Trade Division, we were able to assign the TSUS product codes associated with each antidumping suit to a four-digit 1972 SIC industry and to determine the total number of TSUS product codes in each SIC industry as well. Because TSUS codes are based on traded products and SIC code assignments are based on a firm's principal productive activities, several SIC industries do not have any TSUS codes associated with them during our sample. Consequently, an SIC industry appears in our data set only if it contains at least one TSUS product code for each year of our sample. Only four industries were deleted from the sample because they had no TSUS code in them for only a portion of the sample time period. Most of the industries omitted had no TSUS codes in them for all years. This concordance procedure left a total of 338 industries for our time period of $1980-85$.

\section{Econometric Model}

Our econometric model should capture several aspects of the economic environment we are considering. The first is the joint determination of the decision to file an antidumping suit with the level of imports and domestic output. We model the contemporaneous correlation between the level of imports and domestic output and the decision to file an antidumping suit by the presence of an unobservable industry characteristic that affects the mean of each of these three variables. Our econometric model allows for both contemporaneous correlations and 
correlation over time among these three variables. Because the model uses functions of lagged values of the levels of imports and domestic output as regressors to predict antidumping-suit filing activity, we must account for the correlation between these functions of lagged dependent variables and the autocorrelation in the error terms of the suit-filing model, or the resulting parameter estimates will be inconsistent.

The suit-filing process has several characteristics that we attempt to capture in our econometric model. First, antidumping suits are filed at the TSUS code level, although all of our remaining data are at the fourdigit SIC level. Consequently, the model must allow us to recover information about the TSUS code-level filing process using SIC industry-level data as regressors for the filing rate process. The number of filings in a given TSUS code is a nonnegative, discrete-valued, random variable that is zero for most time periods, but which can take on large positive values when it is nonzero. We select a discrete distribution for the TSUS code-level number of antidumping suit filings that allows for this large positive skew in the distribution of filings for a given industry. Because there are both observable and unobservable reasons for persistently high levels of filing activity, we include an unobservable industry-specific propensity to file suits, which also affects the level of imports and output from the competing domestic industry. In addition, to match the industry-level aggregation of our import and domestic output data, we need a distribution for TSUS level filings which can be aggregated to the four-digit SIC level in an empirically tractable manner.

To measure the impacts of various stages of the antidumping suit resolution process on the flow of imports and domestic output in a consistent manner, several characteristics of the suit resolution process must be taken into account. First, a single antidumping investigation can straddle more than a single year, while each of the various stages of the process lasts only a fraction of a year. In addition, several antidumping suits can be pending against the same product imported from different countries and therefore be simultaneously active in a single TSUS code. Finally, our data on imports and domestic output are available at the four-digit SIC level only on an annual basis. Consequently, the appropriate model must allow us to recover the TSUS code-level impacts on the flows of imports and domestic output from stages of the suit resolution process that may run over adjacent years 
or for a fraction of a year, accounting for the possibility of multiple filings from the same TSUS code, using data that are time aggregated to annual magnitudes and cross-sectionally aggregated to the four-digit SIC industry level. Our TSUS code-level, within-year, flow model provides a framework for us to recover within-year effects from annual import and domestic output levels using indexes of suit activity in that year.

Our SIC industry-level model of the filing rate process and the impacts of the suit resolution process can be interpreted without reference to the underlying TSUS code-level processes. Our bottom-up approach, however, starting with a TSUS code-level model that has not been timeaggregated to the annual magnitudes, specifies an econometric model at the level of both time and product aggregation at which the true underlying processes are occurring. It is then both time- and productaggregated to an industry-level model. This modeling strategy allows the recovery of both TSUS code- and industry-level effects because the industry-level model is obtained from the explicit aggregation of the TSUS code-level model.

We now describe the details of our econometric model of suit-filing behavior and the effects of that behavior on the level of imports and domestic output. Let $f_{g i t}$ be the number of antidumping suits filed in industry $i$ for good $g$ in time period $t$, where $g=1, \ldots$, $G_{i t}, t=1, \ldots, T$, and $i=1, \ldots, N$. Because antidumping suits are filed at the TSUS code level, for the purposes of this paper a good is defined to be a TSUS product code.

Let $\lambda_{g i t}$ denote the rate at which suits are filed in industry $i$ for good $g$ in period $t$. We assume that the distribution of $f_{g i t}$ given $\lambda_{g i t}$ is Poisson, $P(\lambda)$, with parameter $\lambda=\lambda_{g i t}$. We denote this fact using the notation

$$
f_{g i t} \mid \lambda_{g i t} \sim P\left(\lambda_{g i t}\right) \text {. }
$$

These assumptions are consistent with $f_{g i t}$ being a Poisson point process for the time interval $t$ to $t+1$.

We further assume that $\lambda_{g i t}$ possesses a gamma distribution $\Gamma\left(\mu_{i t}, \sigma\right)$, where $\mu_{i t}=\exp \left(\boldsymbol{X}_{i t}^{\prime} \boldsymbol{\gamma}+\boldsymbol{\theta}_{i}\right)$. The vector $\boldsymbol{X}_{i t}$ contains the observable characteristics of industry $i$ at the beginning of time period $t$ that affect its filing rate; the vector $\gamma$ and the scalar $\sigma$ are parameters to be estimated. The variable $\theta_{i}$ is the unobservable propensity of firms in industry $i$ to file antidumping suits. One industry may have a larger 
number of filings than another industry for many unobservable or nonquantifiable reasons. We account for this unobservable difference in behavior across industries by $\theta_{i}$. We assume that $\theta_{i}$ is independently and identically distributed across industries and remains constant over time. Using our above notation we have

$$
\lambda_{g i t} \mid X_{i t}, \theta_{i} \sim \Gamma\left[\exp \left(\boldsymbol{X}_{i t}^{\prime} \boldsymbol{\gamma}+\theta_{i}\right), \sigma\right] .
$$

Assumption 2 implies that each product class within industry $i$ and in time period $t$ has a different mean rate of filing $\left(\lambda_{g i t}\right)$, although all of these filing rates are drawn from the same gamma distribution.

Combining assumptions 1 and 2, we have

$$
f_{g i t} \mid \boldsymbol{X}_{i t}, \theta_{i} \sim P\left(\lambda_{g i t}\right) \mathbf{o}_{\lambda_{g i t}} \Gamma\left[\exp \left(\boldsymbol{X}_{i t}^{\prime} \boldsymbol{\gamma}+\theta_{i}\right), \boldsymbol{\sigma}\right],
$$

where $\mathbf{o}_{\lambda_{g i t}}$ denotes compounding or mixing the parameter $\lambda_{g i t}$ of the Poisson distribution with a gamma distribution $\Gamma\left[\exp \left(\boldsymbol{X}_{i t}^{\prime} \boldsymbol{\gamma}+\theta_{i}\right), \sigma\right]$. Results from Johnson and Kotz imply that $f_{\text {git }}$ has a negative binomial distribution with parameters $\sigma$ and $\mu_{i t}=\exp \left(\boldsymbol{X}_{i t}^{\prime} \boldsymbol{\gamma}+\theta_{i}\right){ }^{22}$ We abbreviate this as $f_{\text {git }} \sim N B\left(\sigma, \mu_{i t}\right)$. This discrete density takes the following form:

$$
\operatorname{pr}\left[f_{g i t}=k\right]=\left(\begin{array}{c}
\sigma+k-1 \\
\sigma-1
\end{array}\right)\left(\mu_{i t}^{f}\right)^{k}\left(1+\mu_{i t}^{f}\right)^{-(\sigma+k)} .
$$

We assume that conditional on $\theta_{i}, f_{g i t}$ is independent of $f_{h j s}$ for all $g \neq h, i \neq j$, and $s \neq t$.

This distribution for $f_{g i t}$ has the following properties. The mean is $\sigma \mu_{i t}$, and the variance is $\sigma \mu_{i t}\left(1+\mu_{i t}\right)$. The parameter $\sigma$ affects the shape of the density of $f_{\text {git }}$. If $\sigma \mu_{i t}<\left(1+\mu_{i t}\right)$, then the mode of $f_{g i t}$ is zero. A sufficient condition for this inequality to hold is $\sigma<1$. The smaller $\sigma$ becomes, the greater is the probability associated with the event $f_{g i t}=0$. Larger values of $\mu_{i t}$ increase the relative probability associated with larger values of $f_{g i t}$. The mode of the density is increasing in $\sigma \mu_{i t}-\left(1+\mu_{i t}\right)$ when $\sigma \mu_{i t}>\left(1+\mu_{i t}\right)$. Because antidumping filings are a relatively rare event, we expect $\sigma$ to be substantially less than one, reflecting the fact that $f_{g i t}=0$ is a highly probable event.

Our data generation process captures the following logic. In each

22. Johnson and $\operatorname{Kotz}$ (1969, ch. 5). 
period $t, \lambda_{g i t}$, the filing rate for product class $g$ in industry $i$, is drawn from a $\Gamma\left[\exp \left(\boldsymbol{X}_{i t}^{\prime} \boldsymbol{\gamma}+\boldsymbol{\theta}_{i}\right], \sigma\right)$ distribution. Conditional on this draw of $\lambda_{g i t}$ and the value of $\theta_{i}$, the actual filing behavior for an individual product class evolves according to a Poisson process with rate $\lambda_{\text {git }}$. This compound distribution model allows for differences in filing rates across product classes within an industry, while imposing the restriction that, on average, all products within an industry file at the same rate. From our estimation procedure we can recover estimates of the parameters of both the distribution $\Gamma\left[\exp \left(\boldsymbol{X}_{i t}^{\prime} \boldsymbol{\gamma}+\theta_{i}\right), \sigma\right]$ and the Poisson filing process conditional on the realized value of $\lambda_{g i t}$.

When the filing of an antidumping suit does occur, the number of product-level filings tends to cluster. For our sample of 2,028 industry and year observations (338 industries times six years), only 122 have nonzero values of antidumping suit activity. Product-level filing activity can be large, however, on the order of hundreds of TSUS product codes, in a given industry and year. Within the context of our econometric model, we can think of this clustering of suits as caused by the positive skewness in the gamma distribution for $\lambda_{\text {git }}$, so that most realizations of the rate of the Poisson process are very small. Very rarely, a large realization does occur, which in turn implies a large number of observed filings. In addition, the unobserved heterogeneity across industries represented by $\theta_{i}$ allows for a much larger (or smaller) level of filing activity from a given industry than its observable characteristics predict. Both the stochastic nature of the mean filing rate and the unobservable industry-level heterogeneity in the filing rate allow for a substantial amount of variability in the TSUS code product-level filing rates across industries.

To compute $f_{i t}$, the total number of suits filed within industry $i$ during period $t$, we sum $f_{g i t}$ from $g=1$ to $G_{i t}$, the total number of TSUS product codes within industry $i$ in period $t$. This summation yields

$$
f_{i t}=\sum_{g=1}^{G_{i t}} f_{g i t} .
$$

This annual amount of industry-level filing activity is the observable dependent variable used to estimate the parameters $\gamma$ and $\sigma$ and the across-industry distribution of heterogeneity $f(\theta)$.

To construct the conditional density of $f_{i t}$ given $\theta_{i}$, we utilize the fact 
that the sum of two independent $N B(\alpha, \beta)$ random variables is $N B(2 \alpha, \beta)$. This implies that $f_{i t}$ possesses a negative binomial distribution with parameters $G_{i t} \sigma$ and $\mu_{i t}=\exp \left(\boldsymbol{X}_{i t}^{\prime} \gamma+\theta_{i}\right)$, conditional on the value of $\theta_{i}$. Consequently, the conditional distribution of $f_{i t}$ given $\theta_{i}$ is

(6) $\operatorname{pr}\left(f_{i t} \mid \theta_{i}\right)=\frac{\Gamma\left(G_{i t} \sigma+f_{i t}\right)}{\Gamma\left(f_{i t}+1\right) \Gamma\left(G_{i t} \sigma\right)}$

$$
\times \exp \left[f_{i t}\left(\boldsymbol{X}_{i t}^{\prime} \boldsymbol{\gamma}+\boldsymbol{\theta}_{i}\right)\right]\left[1+\exp \left(\boldsymbol{X}_{i \boldsymbol{i} \boldsymbol{\gamma}}^{\prime}+\theta_{i}\right)\right]^{-\left(G_{i t} \boldsymbol{\sigma}+f_{i t}\right)}
$$

where $\Gamma(\alpha)$ is the gamma function

$$
\Gamma(\alpha)=\int_{0}^{\infty} t^{\alpha-1} e^{-t} d t .
$$

We have also made use of the relationship $\Gamma(\alpha+1)=\alpha$ !. The joint density function of $f_{i}=\left(f_{1980, i}, f_{1981, i}, \ldots, f_{1985, i}\right)$ is

$$
\operatorname{pr}\left(f_{i} \mid \theta_{i}\right)=\prod_{t=1980}^{1985} \operatorname{pr}\left(f_{i t} \mid \theta_{i}\right)
$$

where $\operatorname{pr}\left(f_{i t} \mid \theta_{i}\right)$ is defined in equation 6 . Henceforth, let $t=1, \ldots, T=6$, denote the years 1980-85.

We now turn to our model of the impact of antidumping duties on industry-level imports and output, which is linked to the model of filing activity through the unobserved industry propensity for filing, $\theta_{i}$. We first specify the product class import equation and output prediction equations and then aggregate these to obtain the industry-level equations. Let $I M P_{g i t}$ denote the level of imports for product class $g$ in industry $i$ in time period $t$. Let $O U T_{g i t}$ denote the level of output produced domestically in product class $g$ in industry $i$ in time period $t$. We treat time period $t$ as the interval of time $[t, t+1)$.

Because our goal is to measure the within-year effects of the stages of the antidumping suit resolution process using annual data, we first specify a model for the within-year flow of imports and domestic output that incorporates how each stage of the process affects those flows. We then aggregate each of these two within-year flow equations to an annual level to obtain equations that incorporate how each stage of the antidumping suit resolution process affects the annual totals of imports and domestic output. This aggregation process produces indexes of annual 
suit activity consistent with our model of import and domestic output flows. Aggregating these TSUS code-level, annual-level equations for all products in each four-digit SIC industry yields equations that can be estimated using our annual industry-level data. This aggregation process clarifies precisely how our annual industry-level indexes of dumping suit activity are constructed from the product-level indexes.

Our within-year model of the impacts of antidumping duties assumes that for any year $t$ and industry $i$, the following linear differential equations characterize the instantaneous annual rate of change in the real value of imports and domestic output at the TSUS code level:

$$
\frac{d I M P_{g i t}}{d s}=\beta^{m} \theta_{i}+\xi_{t}^{m}+\beta_{1}^{m} I_{g i t}^{O G D}(s)+e_{g i t}(m),
$$

and

$$
\frac{d O U T_{g i t}}{d s}=\beta^{o} \theta_{i}+\xi_{t}^{o}+\beta_{1}^{o} I_{g i t}^{O G D}(s)+e_{g i t}(o),
$$

where $\beta^{k},(k=m, o)$ are coefficients quantifying the impact of the unobservable industry heterogeneity on the rate of change of the real value of imports and output in industry $i$ for all time and $\xi_{t}^{k},(k=m, o)$ are fixed time effects for the two rates of change for year $t$. The variable $I_{\text {git }}^{O G D}(s)$ counts the number of currently ongoing antidumping duties $(O G D)$ for all $s \in(t, t+1)$ in product class $g$ in industry $i$ and time period $t$. The coefficients $\beta_{l}{ }^{k},(k=m, o)$ quantify the effect of a oneunit change in these count variables on the annual rate of imports and domestic output for good $g$ in industry $i$ during time period $t$. The variables $e_{g i t}(k),(k=m, o)$ are independent, identically distributed shocks to the rate of imports and output for product class $g$, in industry $i$, in period $t$. We assume that the disturbance vector $\boldsymbol{e}_{\boldsymbol{g} i t}=\left[e_{g i t}(m)\right.$, $\left.e_{g i t}(o)\right]^{\prime}$ possesses a bivariate normal distribution with mean zero and covariance matrix $\Sigma$. We assume that $\boldsymbol{e}_{\boldsymbol{g} i t}$ is independently and identically distributed across goods and industries and over time.

For a dumping duty to be imposed and, hence, for $I_{g i t}^{O G D}(s)$ to take on a positive value, final determinations must have been made that sales were at less than fair value and that injury resulted from dumped imports. Both of these decisions are made by established administrative procedures that are not affected by the specific domestic industry under consideration. Consequently, we would not expect the treatment of 
individual firms in an antidumping investigation to be influenced by $\theta_{i}$, the unobserved propensity of firms in industry $i$ to file antidumping suits. For the purposes of our econometric model, this neutrality of the resolution process with respect to the specific domestic industry under consideration implies that $\theta_{i}$ is independent of the value of $I_{g i t}^{O G D}(s)$, which reflects the joint decision of the ITA and ITC to impose antidumping duties. Although the actual operation of the suit resolution process favors this econometric assumption, to specify a model that allows for the possible correlation between the decision by the ITC and ITA to impose duties and the unobserved propensity of the affected industry to file a suit would require specifying and estimating a model of the joint decisionmaking process of the ITC and the ITA. Such a model would have to predict both the outcome and the duration of each stage of the suit resolution process because both of these factors enter into the construction of the annual indexes of industry-level antidumping suit activity used in our econometric model of imports and domestic output. Given the complex nature of each of these administrative processes, we leave this difficult task to future research.

To clarify how antidumping duties affect the quantity of imports and domestic output, consider the following example. Suppose that no antidumping duties are currently imposed on imports from product class $g$ in industry $i$ during year $t$. In this case the rate of imports in product class $g$ in industry $i$ is

$$
\frac{d I M P_{g i t}}{d s}=\beta^{m} \theta_{i}+\xi_{t}^{m}+e_{g i t}(m) .
$$

Suppose that antidumping duties are imposed on imports in this product class sometime during period $t$. The variable $I_{g i t}^{O G D}(s)$ will then take on the value 1 for all $s \in(t, t+1)$, such that antidumping duties are currently active for that product class, and the rate of imports will thus increase by the value of $\beta_{1}^{m}$. Should another set of duties be imposed on imports within this product class during the same time interval, then $I_{g i t}^{O G D}(s)$ will take on the value 2 for as long as both sets of duties are active; it will return to the value 1 when a single set of duties is again active and to zero when no duties are active. ${ }^{23}$

23. Our earlier discussion characterized the effects of the duties and other stages of the suit resolution process in terms of the quantity of imports and domestic output at the 
Continuing with the derivation of our TSUS product code-level import and output equations, we integrate equations 8 and 9 with respect to $s$ from $t$ to $t+1$ to obtain

$$
I M P_{g i t}=\beta^{m} \theta_{i}+\xi_{t}^{m}+\beta_{1}^{m} O G D_{g i t}+e_{g i t}(m)
$$

and

$$
O U T_{g i t}=\beta^{o} \theta_{i}+\xi_{t}^{o}+\beta_{i}^{o} O G D_{g i t}+e_{g i t}(o)
$$

where

$$
O G D_{g i t}=\int_{t}^{t+1} I_{g i t}^{O G D}(s) d s
$$

To compute industry-level import and output equations from these product-level equations, we must aggregate equations 11 and 12 over the product classes $g$ within industry $i$ in period $t$. Summing over all $g$ yields

$$
I M P_{i t}=\beta^{m} \theta_{i} G_{i t}+\xi_{t}^{m} G_{i t}+\beta_{1}^{m} O G D_{i t}+\eta_{i t}(m)
$$

and

$$
O U T_{i t}=\beta^{o} \theta_{i} G_{i t}+\xi_{t}^{o} G_{i t}+\beta_{i}^{o} O G D_{i t}+\eta_{i t}(o),
$$

where

seven-digit TSUS level. Our data on imports, domestic output, and the industry-level output price deflator are at the four-digit SIC level. Thus, data limitations prevent us from deriving an index of the quantity of output at the four-digit SIC level. To do this would require prices and revenue shares for all of the seven-digit TSUS products in each of the four-digit SIC industries. As a result, our estimates reflect real value effects instead of quantity effects. So long as the elasticity of demand for each of these products is larger than one in absolute value, the quantity and value effects should go in the same direction. The assumption of elastic demand for goods produced by these domestic industries and their foreign competitors is consistent with available empirical evidence. Consequently, our empirical results are useful to test the sign predictions of our theories concerning the effects of the various stages of the suit resolution process on the quantity of imports and domestic output despite our use of the real value of imports and output data. 


$$
\begin{gathered}
I M P_{i t}=\sum_{g=1}^{G_{i t}} I M P_{g i t}, O U T_{i t}=\sum_{g=1}^{G_{i t}} O U T_{g i t}, \\
O G D_{i t}=\sum_{g=1}^{G_{i t}} O G D_{g i t}, \text { and } \eta_{i t}(k)=\sum_{g=1}^{G_{i t}} e_{g i t}(k),
\end{gathered}
$$

for $k=m, o$. This aggregation procedure implies that $\boldsymbol{\eta}_{i t}=$ $\left[\eta_{i t}(m), \eta_{i t}(o)\right]^{\prime}$ is $N\left(0, G_{i t} \Sigma\right)$, so that $\boldsymbol{\eta}_{i t}$ is heteroscedastic conditional on $G_{i t}$. Dividing equations 13 and 14 by $G_{i t}$ yields a model more amenable to estimation. This form of the model is analogous to the conventional fixed time effects, random individual effects, panel data model. The model is

$$
I M P_{i t} / G_{i t}=\mu_{i t}^{m}+\eta_{i t}(m) / G_{i t} \text { and } O U T_{i t} / G_{i t}=\mu_{i t}^{o}+\eta_{i t}(o) / G_{i t},
$$

where

$$
\begin{aligned}
& \mu_{i t}^{m}=\beta^{m} \theta_{i}+\xi_{t}^{m}+\beta_{1}^{m} O G D_{i t} / G_{i t} \text { and } \\
& \mu_{i t}^{o}=\beta^{o} \theta_{i}+\xi_{t}^{o}+\beta_{1}^{o} O G D_{i t} / G_{i t} .
\end{aligned}
$$

The variables $\mu_{i t}^{m}$ and $\mu_{i t}^{o}$ are the conditional means of the normalized annual imports and output from industry $i$ in period $t$. The normalized duty count variable can now be interpreted as an intensity of suit activity. The normalized error vector $\eta_{i t} / G_{i t}$ is still heteroscedastic because of the distribution for $\boldsymbol{\eta}_{i t}$ given above. Consequently, we apply the appropriate weighting scheme in the construction of the likelihood function.

Several comments are in order about the structure of our econometric model. First, an assumption implicit in equations 15 and 16 is that $\beta_{1}^{m}$ and $\beta_{1}^{o}$, the coefficients measuring the impact of an antidumping duty on the flow of imports and domestic output, are the same across all products and industries. We experimented with random coefficient assumptions for these impact coefficients, where the coefficient for each industry is assumed to be drawn from an unknown distribution, but this did not produce a statistically superior description of the data. An alternative strategy to constructing $O G D_{i t}$, our index of dumping duty activity within an industry, would be to weight $O G D_{g i t}$ by the share of industry-level imports or domestic output attributable to products in each specific TSUS code. Value weighting in this manner is inconsistent with our underlying TSUS code within-year model of the impacts of 
antidumping duties, however. We would be weighting each $O G D_{g i t}$ by a function of either $I M P_{g i t}$ or $O U T_{g i t}$, both of which are functions of $\theta_{i}$ and an element of $\boldsymbol{e}_{g i t}$. Within the context of our model, this would imply contemporaneous correlation between the regressors, the importor output-weighted indexes of duty activity, and the error terms in the import and output equations, thus rendering our coefficient estimates inconsistent. ${ }^{24}$

Because we assume that $G_{i t}$ is known at the beginning of each year, aggregating over the number of TSUS codes within a given four-digit SIC does not introduce any correlation between $O G D_{i t}$ and $\theta_{i}$ or $\boldsymbol{e}_{g i t}$. So long as we assume that the probability that duties are imposed given that a suit has been filed does not depend on $\theta_{i}$, our estimation procedure will yield consistent estimates of $\beta_{1}^{m}$ and $\beta_{1}^{o}$.

Using our distributional assumptions, we construct the joint density of $I M P_{i}^{*}=\left(I M P_{i 1} / G_{i 1}, \ldots, I M P_{i T} / G_{i T}\right)^{\prime}$ and $\boldsymbol{O U} \boldsymbol{T}_{i}{ }^{*}=\left(O U T_{i 1} /\right.$ $\left.G_{i 1}, \ldots, O U T_{i T} / G_{i T}\right)^{\prime}$ conditional on $\theta_{i}$ as follows. Conditional on the value of $\theta_{i}$, the joint density of the two-dimensional vector $\left(I M P_{i t} / G_{i t}\right.$, $\left.O U T_{i t} / G_{i t}\right)$ is

$$
\begin{gathered}
\phi\left(I M P_{i t} / G_{i t}, O U T_{i t} / G_{i t} \mid \theta_{i}\right)= \\
\frac{1}{2 \pi}\left|G_{i t}^{-1} \sum\right|^{-1 / 2} \exp \left\{-1 / 2\left[\boldsymbol{v}_{i t}^{\prime}\left(G_{i t}^{-1} \sum\right)^{-1} \boldsymbol{v}_{i t}\right]\right\}
\end{gathered}
$$

where $\boldsymbol{v}_{i t}=\left[\left(I M P_{i t} / G_{i t}-\mu_{i t}^{m}\right),\left(O U T_{i t} / G_{i t}-\mu_{i t}^{o}\right)\right]^{\prime}$. This implies that the joint density of $\left(\boldsymbol{I M P}_{i}{ }^{*}, \boldsymbol{O U} \boldsymbol{T}_{i}{ }^{*}\right)^{\prime}$ conditional on $\theta_{i}$ is

$$
h\left(\operatorname{IMP}_{i}^{*}, \boldsymbol{O U T}_{i}^{*} \mid \theta_{i}\right)=\prod_{t=1}^{T} \phi\left(I M P_{i t} / G_{i t}, O U T_{i t} / G_{i t} \mid \theta_{i}\right)
$$

Combining this joint density with the joint density of filings over the sample period yields the following joint density of filings, output, and imports conditional on $\theta_{i}$ :

$$
g\left(f_{i}, \text { IMP }_{i}^{*}, \text { OUT }_{i}^{*} \mid \theta_{i}\right)=h\left(\operatorname{IMP}_{i}^{*}, \text { OUT }_{i}^{*} \mid \theta_{i}\right) \operatorname{pr}\left(f_{i} \mid \theta_{i}\right) .
$$

24. We have also estimated normalized import and output equations analogous to equation 15 but with the import penetration ratio and the capacity utilization rate, rather than imports and output, on the left-hand side. Although there is no consistent method of aggregation from the product-code level that would generate such models, the results from their estimation are qualitatively similar, in terms of the signs and relative magnitudes of coefficient estimates, to the results we report here. 
To complete the construction of the unconditional joint density of filings, output, and imports over our sample period for any industry, we must integrate this conditional density with respect to the density of $\theta$. We choose a discrete factor approximation to this unknown density. Recent Monte Carlo work by Mroz and Guilkey has found that these discrete factor structures are able to model a wide variety of potential heterogeneity distributions. ${ }^{25}$ For many models involving discrete and continuous endogenous variables, the parameters of the conditional distribution of interest estimated from these models were found to dominate those obtained from the maximum likelihood estimator in terms of mean-squared-error loss for the sample sizes considered. Integrating with respect to this discrete density of $\theta,\left(\pi_{k}, \theta_{k}\right) k=1, \ldots, K$, where $K$ is the number of points of support of the discrete density and $\pi_{k}$ the probability associated with the point of support $\theta_{k}$, yields

$$
p\left(f_{i}, \boldsymbol{I M P}_{i}^{*}, \boldsymbol{O U T}_{i}^{*}\right)=\sum_{k=1}^{K} \pi_{k} g\left(f_{i}, \boldsymbol{I M P}_{i}^{*}, \boldsymbol{O U T}_{i}^{*} \mid \theta_{k}\right) .
$$

Taking the $\log$ of $p\left(f_{i}, \boldsymbol{I M P}_{i}{ }^{*}, \boldsymbol{O U} \boldsymbol{T}_{\boldsymbol{i}}{ }^{*}\right)$ and summing from $i=1$ to $N$ yields the log-likelihood function for our model. For all of our estimation results, we found that beyond $K=2$, the parameter estimates of the three conditional mean functions and their standard error estimates did not change appreciably. Consequently, all results reported in this paper are conditional on the value $K=2$ for the number of points of support of the assumed discrete distribution for $\theta_{i}$. In their Monte Carlo study, Mroz and Guilkey also found that only a small number of points of support are necessary to estimate adequately the parameters of economic interest.

In summary, the essential features of the joint density of $\boldsymbol{f}_{i}, \boldsymbol{I M P} \boldsymbol{P}_{\boldsymbol{i}}{ }^{*}$, and $\boldsymbol{O U} \boldsymbol{T}_{i}{ }^{*}$ captured by our econometric modeling framework are these: this model allows correlation over time between each of the six elements of each of these three vectors and between any element of these three vectors and any other element in the remaining two vectors. Consequently, a fairly rich class of correlation structures among these eighteen variables (three vectors of six elements) can be accounted for in estimating the parameters of the conditional mean functions of the three variables using our modeling framework.

25. Mroz and Guilkey (1991). 
We now discuss the variables entering $\boldsymbol{X}_{i t}$, the vector of observable industry characteristics shifting the conditional mean of the filing rate of industry $i$ and time period $t$. Our main objective in selecting variables for inclusion in $\boldsymbol{X}_{i t}$ follows from the logic that if industries are aware that particular variables are used to determine injury in an antidumping suit proceeding, then these variables should predict future dumping suit activity (under the outcome-filer strategy). Although the domestic industry must concern itself with establishing injury, a determination that foreign firms have sold goods in the domestic market at less than fair market value is also necessary for dumping to be found. Moreover, the margin by which the Commerce Department finds that sales to the domestic market are made at less than fair value determines the magnitude of the antidumping duties that the petitioning industry can expect. Nevertheless, this margin is extremely unpredictable, and there are upward biases inherent in the process used to determine its level. This uncertainty results in part from the different methodologies that can be used, sometimes in a single suit, to determine this margin. ${ }^{26}$ For these reasons, we hypothesize that firms base their decisions to file dumping suits primarily on the observable industry characteristics that determine injury, and we allow for a sufficiently rich stochastic structure to account for unobservable differences in filing behavior across industries.

A major indicator of injury to the petitioning firms is the import penetration ratio $I M P E N_{i t}=I M P_{i t} /\left(I M P_{i t}+O U T_{i t}\right)$. A large value of IMPEN indicates a large foreign presence in the domestic market that may injure the domestic firms. A second variable used to assess injury is the domestic firm's capacity utilization rate, which we represent at the industry level by $C A P U_{i t}=O U T_{i t} / C A P_{i t}$ (where $O U T_{i t}$ is real shipments and $C A P_{i t}$ is real capital stock). We compute $O U T_{i t}$ as the nominal value of annual shipments divided by the price index for industryspecific shipments. All real magnitudes are in 1972 dollars. We include $I M P E N_{i t-1}$ and $C A P U_{i t-1}$ in $\boldsymbol{X}_{i t}$, because they are both predetermined as of the beginning of year $t$. We also include time fixed effects in $\boldsymbol{X}_{i t}$

26. Several papers in Boltuck and Litan (1991) discuss the large amount of uncertainty inherent in the process for setting dumping margins. A conclusion, fairly consistent throughout most of the papers in that volume, is that there are strong biases in the process that favor finding a positive margin. The papers by Francois, Palmeter, and Anspacher and by Boltuck, Francois, and Kaplan are particularly persuasive in this regard. 
to account for any trends in filing activity not reflected in changes in observable or unobservable industry characteristics.

Finally, we include several additional variables to account for the fact that the magnitudes of IMPEN and CAPU necessary to find harmful dumping may vary with the size and the structure of the domestic industry. We measure the size of an industry by $E M P_{i t}$, aggregate employment for industry $i$ in period $t$, and expect that a given level of $I M P E N$ and $C A P U$ is more likely to be associated with a finding of injury the larger the size of the industry. We attempt to use value added per dollar of output in the industry, $V A D D_{i t} / O U T_{i t}$, as a proxy for the (vertical) structure of an industry and expect that a given level of IMPEN and CAPU is more likely to be associated with a finding of injury to the domestic industry the lower is $V A D D / O U T$, that is, the farther downstream the domestic industry is located, the smaller the share of primary factor payments in total industry cost, and the more sensitive those factor payments will be to industry price changes. Because they are predetermined at the beginning of year $t$, lagged values of $V A D D / O U T$ and EMP (their values for period $t-1$ ) are included in $\boldsymbol{X}_{i t}$.

Before describing our results, we should note some properties of our econometric model. Three of the variables in $\boldsymbol{X}_{i t}$ are functions of lagged values of $I M P_{i t}$ and $O U T_{i t}$. The presence of $\theta_{i}$ in the $I M P_{i t-1}$ and $O U T_{i t-1}$ equations implies that $I M P E N_{i t-1}, C A P U_{i t-1}$, and $V A D D_{i t-1} / O U T_{i t-1}$, which are elements of $\boldsymbol{X}_{i t}$ in $\mu_{i t}=\exp \left(\boldsymbol{X}_{i t}^{\prime} \boldsymbol{\gamma}+\boldsymbol{\theta}_{i}\right)$, are each functions of $\theta_{i}$. However, the Jacobian of the transformation from the vector of composite disturbances in the $\boldsymbol{f}_{\boldsymbol{i}}, \boldsymbol{I M \boldsymbol { P } _ { i }}{ }^{*}$, and $\boldsymbol{O U} \boldsymbol{T}_{i}{ }^{*}$ equations (each of which contains $\left.\boldsymbol{\theta}_{i}\right)$ to the vector $\left(\boldsymbol{f}_{i}, \boldsymbol{I M P}_{\boldsymbol{i}}^{*}, \boldsymbol{O U} \boldsymbol{U}_{\boldsymbol{i}}{ }^{*}\right)$ is triangular with 1 's along the diagonal, so that its determinant is equal to one. Consequently, our likelihood function correctly accounts for this correlation between the regressors and error term in the filing rate equations, so that the maximum likelihood estimates are consistent estimates of the true parameter values.

Table 1 contains the sample means and standard errors for all of the variables used in our analysis. The most noticeable aspect of this table is the large estimated standard deviations, relative to their means, associated with the number of filings and the various indexes of suit activity given in the lower rows of the table. This is consistent with the "rare event" nature of antidumping suit activity. Another aspect of 
Table 1. Means and Standard Deviations of Variables

\begin{tabular}{|c|c|c|c|}
\hline Variable & Definition & Mean & Standard deviation \\
\hline$f_{i t}$ & Total filings & 0.928 & 13.69 \\
\hline$G_{i t}$ & Total TSUS codes & 33.63 & 131.86 \\
\hline$I M P_{i t}$ & $\begin{array}{l}\text { Real imports in millions of } \\
1972 \text { dollars }\end{array}$ & 291.14 & 1151.19 \\
\hline$O U T_{i t}$ & $\begin{array}{l}\text { Real output in millions of } \\
1972 \text { dollars }\end{array}$ & 2168.61 & 4161.81 \\
\hline$E M P_{i t}$ & $\begin{array}{l}\text { Industry-level employment } \\
\text { in thousands }\end{array}$ & 40.86 & 62.18 \\
\hline$V A D D_{i t} / O U T_{i t}$ & $\begin{array}{l}\text { Value added per dollar of } \\
\text { real output }\end{array}$ & 0.482 & 0.134 \\
\hline$C A P U_{i t}$ & Capacity utilization rate & 2.799 & 1.899 \\
\hline$I_{M P E N}$ & Import penetration ratio & 0.119 & 0.149 \\
\hline$O G P_{i t}$ & $\begin{array}{l}\text { Ongoing antidumping } \\
\text { petition }\end{array}$ & 0.547 & 8.556 \\
\hline$O G P L F V_{i t}$ & $\begin{array}{l}\text { Ongoing preliminary less- } \\
\text { than-fair-value }\end{array}$ & 0.159 & 2.711 \\
\hline OGSUS $_{i t}$ & Ongoing suspension & 0.177 & 3.418 \\
\hline$O G W D_{i t}$ & Ongoing withdrawal & 0.558 & 12.047 \\
\hline$O G D_{i t}$ & Ongoing duties & 0.300 & 3.312 \\
\hline UNION79 $_{i}$ & $\begin{array}{l}\text { Percent of industry's } \\
\text { workers unionized in } \\
1.979\end{array}$ & 32.47 & 12.43 \\
\hline
\end{tabular}

Source: Authors' calculations, based on 2,208 year-industry observations $(i=1, \ldots, N=338$ industries and $t=1, \ldots$, $\mathrm{T}=6$ years).

note concerns the number of TSUS codes per industry. Although the mean number of TSUS codes is 33.63 , the standard deviation indicates a substantial amount of variability in this number across industries and over time.

\section{Results}

The first column of table 2 presents estimates of the parameters of the filing rate equation. The first column of tables 3 and 4 presents estimates of the parameters of the conditional mean functions, given in equation 16, that are used to assess the impact of duties on the flow of both imports and domestic output. The results are consistent with the "outcome-filer" strategy; we find that changes in any of the four regressors change the conditional mean of filings in the predicted manner. For example, higher filing rates are associated with industries that exhibit higher import penetration ratios, lower capacity utilization, higher 
Table 2. Filing Rate Equations Estimates

\begin{tabular}{|c|c|c|c|}
\hline \multirow[b]{2}{*}{ Variable } & \multirow{2}{*}{$\begin{array}{c}\begin{array}{c}\text { Single-filing } \\
\text { strategy model }\end{array} \\
\text { Duties-only model }\end{array}$} & \multicolumn{2}{|c|}{ Two-filing strategy model } \\
\hline & & $\begin{array}{l}\text { Outcome-filing } \\
\text { strategy }\end{array}$ & $\begin{array}{c}\text { Process-filing } \\
\text { strategy }\end{array}$ \\
\hline Constant & $\begin{array}{c}3.538 \\
(1.157)\end{array}$ & $\begin{array}{c}3.510 \\
(1.102)\end{array}$ & . \\
\hline$I M P E N_{i t-1}$ & $\begin{array}{c}3.659 \\
(1.599)\end{array}$ & $\begin{array}{c}1.700 \\
(0.534)\end{array}$ & 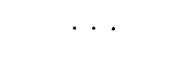 \\
\hline$C A P U_{i t-1}$ & $\begin{array}{r}-0.349 \\
(0.086)\end{array}$ & $\begin{array}{r}-0.425 \\
(0.139)\end{array}$ & $\begin{array}{c}-0.250 \\
(0.117)\end{array}$ \\
\hline$C A P U_{i t-2}$ & $\ldots$ & $\ldots$ & $\begin{array}{r}-0.140 \\
(0.063)\end{array}$ \\
\hline$E M P_{i t-1}$ & $\begin{array}{c}0.009 \\
(0.003)\end{array}$ & $\begin{array}{c}0.009 \\
(0.003)\end{array}$ & $\ldots$ \\
\hline$V A D D_{i t-1} / O U T_{i t-1}$ & $\begin{array}{l}-3.171 \\
(1.806)\end{array}$ & $\begin{array}{r}-2.404 \\
(1.723)\end{array}$ & $\cdots$ \\
\hline$\sigma \times 10^{4}$ & $\begin{array}{c}8.213 \\
(1.173)\end{array}$ & $\begin{array}{c}8.959 \\
(2.045)\end{array}$ & $\begin{array}{c}8.959 \\
(2.045)\end{array}$ \\
\hline YEAR81 & $\begin{array}{r}-0.472 \\
(0.092)\end{array}$ & $\begin{array}{r}-0.518 \\
(0.221)\end{array}$ & $\begin{array}{r}-0.518 \\
(0.221)\end{array}$ \\
\hline YEAR82 & $\begin{array}{r}-0.019 \\
(0.033)\end{array}$ & $\begin{array}{c}0.041 \\
(0.213)\end{array}$ & $\begin{array}{c}0.041 \\
(0.213)\end{array}$ \\
\hline YEAR83 & $\begin{array}{c}0.594 \\
(0.234)\end{array}$ & $\begin{array}{c}0.406 \\
(0.192)\end{array}$ & $\begin{array}{c}0.406 \\
(0.192)\end{array}$ \\
\hline YEAR84 & $\begin{array}{c}0.281 \\
(0.262)\end{array}$ & $\begin{array}{c}0.271 \\
(0.093)\end{array}$ & $\begin{array}{c}0.271 \\
(0.093)\end{array}$ \\
\hline YEAR85 & $\begin{array}{c}0.802 \\
(0.394)\end{array}$ & $\begin{array}{c}0.805 \\
(0.285)\end{array}$ & $\begin{array}{c}0.805 \\
(0.285)\end{array}$ \\
\hline
\end{tabular}

Source: Authors' calculations; $N=338$ industries for $T=6$ years. Standard errors for the coefficient estimates are in parentheses.

employment, and lower shares of primary factor payments in total costs. As the very small value of $\sigma$ indicates, the density of filing implied by our model is extremely positively skewed. Recall that in our mixture model interpretation of the density of filings, the filing rate $\lambda_{g i t}$ is drawn from a $\Gamma\left[\exp \left(\boldsymbol{X}_{i t}^{\prime} \boldsymbol{\gamma}+\boldsymbol{\theta}_{i}\right), \sigma\right]$ distribution. The estimated value of $\sigma$ implies a positively skewed distribution of filing rates. That is, for most goods and time periods, the filing rate is very small, but with a small probability a very large $\lambda_{g i t}$ can be drawn that results in a high level of filing activity during that period. Because $E\left(f_{g i t}\right)=\exp \left(\boldsymbol{X}_{i t}^{\prime} \boldsymbol{\gamma}\right)$ $\times E[\exp (\theta)] \sigma$ implies $\ln \left[E\left(f_{g i t}\right)\right]=X_{i t}^{\prime} \gamma+\ln \{E[\exp (\theta)]\}+\ln (\sigma)$, the elements of $\boldsymbol{\gamma}$, when multiplied by the corresponding element of $\boldsymbol{X}_{i t}$, 
Table 3. Import Equations Estimates

\begin{tabular}{|c|c|c|c|c|}
\hline \multirow[b]{2}{*}{ Variable } & \multicolumn{2}{|c|}{ Single-filing strategy models } & \multicolumn{2}{|c|}{ Two-filing strategy model } \\
\hline & $\begin{array}{c}\text { Duties-only } \\
\text { model }\end{array}$ & $\begin{array}{c}\text { Full } \\
\text { investigation } \\
\text { effects model }\end{array}$ & $\begin{array}{l}\text { Outcome- } \\
\text { filer } \\
\text { model }\end{array}$ & $\begin{array}{l}\text { Process-filer } \\
\text { model }\end{array}$ \\
\hline$O G P_{i r} / G_{i t}$ & $\ldots$ & $\begin{array}{c}8.45 \\
(4.23)\end{array}$ & $\begin{array}{l}12.58 \\
(6.973)\end{array}$ & $\begin{array}{c}-32.58 \\
(12.39)\end{array}$ \\
\hline$O G P L F V_{i r} / G_{i t}$ & $\ldots$ & $\begin{array}{c}-33.81 \\
(10.32)\end{array}$ & $\begin{array}{c}-48.59 \\
(20.39)\end{array}$ & $\begin{array}{c}-3.25 \\
(2.29)\end{array}$ \\
\hline $\operatorname{OGSUS}_{i r} / G_{i t}$ & . . & $\begin{array}{r}-29.57 \\
(8.93)\end{array}$ & $\begin{array}{c}1.33 \\
(4.03)\end{array}$ & $\begin{array}{c}-1.93 \\
(3.09)\end{array}$ \\
\hline$O G W D_{i r} / G_{i t}$ & . & $\begin{array}{c}-17.06 \\
(11.89)\end{array}$ & $\begin{array}{c}-0.04 \\
(2.14)\end{array}$ & $\begin{array}{c}-3.22 \\
(2.98)\end{array}$ \\
\hline$O G D_{i r} / G_{i t}$ & $\begin{array}{r}-10.55 \\
(4.43)\end{array}$ & $\begin{array}{c}-24.95 \\
(9.32)\end{array}$ & $\begin{array}{c}-24.69 \\
(11.20)\end{array}$ & $\begin{array}{r}-14.94 \\
(9.03)\end{array}$ \\
\hline YEAR81 & $\begin{array}{c}-0.052 \\
(0.184)\end{array}$ & $\begin{array}{c}0.090 \\
(0.123)\end{array}$ & $\begin{array}{c}0.065 \\
(0.012)\end{array}$ & $\begin{array}{c}0.065 \\
(0.012)\end{array}$ \\
\hline YEAR82 & $\begin{array}{c}-0.060 \\
(0.238)\end{array}$ & $\begin{array}{c}0.970 \\
(0.632)\end{array}$ & $\begin{array}{c}0.823 \\
(0.603)\end{array}$ & $\begin{array}{c}0.823 \\
(0.603)\end{array}$ \\
\hline YEAR83 & $\begin{array}{c}2.310 \\
(1.032)\end{array}$ & $\begin{array}{c}2.988 \\
(1.323)\end{array}$ & $\begin{array}{c}2.483 \\
(0.948)\end{array}$ & $\begin{array}{c}2.483 \\
(0.948)\end{array}$ \\
\hline YEAR84 & $\begin{array}{c}6.023 \\
(1.843)\end{array}$ & $\begin{array}{c}7.673 \\
(2.232)\end{array}$ & $\begin{array}{c}5.707 \\
(2.394)\end{array}$ & $\begin{array}{l}5.707 \\
(2.394)\end{array}$ \\
\hline YEAR85 & $\begin{array}{c}9.056 \\
(4.493)\end{array}$ & $\begin{array}{l}11.53 \\
(4.393)\end{array}$ & $\begin{array}{c}8.783 \\
(4.203)\end{array}$ & $\begin{array}{c}8.783 \\
(4.203)\end{array}$ \\
\hline
\end{tabular}

Source: Authors' calculations, based on $\mathrm{N}=338$ industries for $\mathrm{T}=6$ years. Standard errors for the coefficient estimates are in parentheses.

have the interpretation of elasticities of the expected number of filings with respect to that element of $\boldsymbol{X}_{i t}$. Evaluating these elasticities for $I M P E N$ and $C A P U$ at the sample means given in table 1 yields values of 0.43 and -0.98 . In other words, if the value of $I M P E N_{i t-1}$ is 1 percent higher for one industry relative to another, then the expected number of filings in the current year should be 0.43 percent higher for this industry, assuming the value of $I M P E N_{i t-1}$ for the other industry is the sample mean of IMPEN. This same elasticity calculation for EMP and $V A D D / O U T$ yields 0.38 and -1.53 , respectively.

We turn now to the effects of antidumping duties on imports and domestic output. The coefficient associated with $O G D$ in table 3 implies that an antidumping duty imposed on a single TSUS code predicts a reduction of $\$ 10.6$ million (in 1972 dollars) in the annual rate of im- 
Table 4. Output Equations Estimates

\begin{tabular}{|c|c|c|c|c|}
\hline \multirow[b]{2}{*}{ Variable } & \multicolumn{2}{|c|}{ Single-filing strategy models } & \multicolumn{2}{|c|}{ Two-filing strategy model } \\
\hline & $\begin{array}{c}\text { Duties-only } \\
\text { model }\end{array}$ & $\begin{array}{c}\text { Full } \\
\text { investigation } \\
\text { effects model }\end{array}$ & $\begin{array}{l}\text { Outcome- } \\
\text { filer } \\
\text { model }\end{array}$ & $\begin{array}{c}\text { Process-filer } \\
\text { model }\end{array}$ \\
\hline$O G P_{i r} / G_{i t}$ & . . & $\begin{array}{r}-7.30 \\
(4.23)\end{array}$ & $\begin{array}{c}-3.25 \\
(4.30)\end{array}$ & $\begin{array}{c}16.94 \\
(10.38)\end{array}$ \\
\hline$O G P L F V_{i r} / G_{i t}$ & $\ldots$ & $\begin{array}{c}24.95 \\
(10.92)\end{array}$ & $\begin{array}{c}9.74 \\
(4.23)\end{array}$ & $\begin{array}{c}3.69 \\
(6.39)\end{array}$ \\
\hline$O G S U S_{i t} / G_{i t}$ & . . & $\begin{array}{c}25.57 \\
(12.93)\end{array}$ & $\begin{array}{l}21.44 \\
(9.49)\end{array}$ & $\begin{array}{c}3.02 \\
(7.83)\end{array}$ \\
\hline$O G W D_{i r} / G_{i t}$ & . . & $\begin{array}{c}14.32 \\
(11.46)\end{array}$ & $\begin{array}{c}10.09 \\
(11.44)\end{array}$ & $\begin{array}{r}-4.47 \\
(4.81)\end{array}$ \\
\hline$O G D_{i r} / G_{i t}$ & $\begin{array}{c}7.13 \\
(5.31)\end{array}$ & $\begin{array}{l}15.97 \\
(6.32)\end{array}$ & $\begin{array}{l}15.55 \\
(9.49)\end{array}$ & $\begin{array}{l}12.46 \\
(8.32)\end{array}$ \\
\hline YEAR81 & $\begin{array}{c}-2.04 \\
(2.79)\end{array}$ & $\begin{array}{c}-7.04 \\
(7.21)\end{array}$ & $\begin{array}{c}1.27 \\
(2.10)\end{array}$ & $\begin{array}{c}1.27 \\
(2.10)\end{array}$ \\
\hline YEAR82 & $\begin{array}{c}-7.32 \\
(5.84)\end{array}$ & $\begin{array}{r}-13.50 \\
(6.20)\end{array}$ & $\begin{array}{c}-6.43 \\
(8.20)\end{array}$ & $\begin{array}{c}-6.43 \\
(8.20)\end{array}$ \\
\hline YEAR83 & $\begin{array}{c}-6.03 \\
(3.04)\end{array}$ & $\begin{array}{r}-7.42 \\
(8.23)\end{array}$ & $\begin{array}{l}-8.29 \\
(10.93)\end{array}$ & $\begin{array}{l}-8.29 \\
(10.93)\end{array}$ \\
\hline YEAR84 & $\begin{array}{c}6.32 \\
(7.50)\end{array}$ & $\begin{array}{c}6.23 \\
(8.02)\end{array}$ & $\begin{array}{c}7.85 \\
(4.74)\end{array}$ & $\begin{array}{c}7.85 \\
(4.74)\end{array}$ \\
\hline YEAR85 & $\begin{array}{c}7.93 \\
(8.94)\end{array}$ & $\begin{array}{c}4.76 \\
(5.94)\end{array}$ & $\begin{array}{c}8.19 \\
(5.75)\end{array}$ & $\begin{array}{c}8.19 \\
(5.75)\end{array}$ \\
\hline
\end{tabular}

Source: Authors' calculations, based on $N=338$ industries for $\mathrm{T}=6$ years. Standard errors for the coefficient estimates are in parentheses.

ports. This same antidumping duty predicts an increase of $\$ 7.1$ million in the annual rate of domestic output of this product, although this effect is too imprecisely estimated to place much confidence in it.

\section{Investigation, Suspension, and Withdrawal Effects}

Although the results reported in the first column of tables 2, 3, and 4 provide estimates of the import and domestic output effects of antidumping duties, we believe these results present an incomplete picture of the trade effects of antidumping law. We now develop an expanded econometric framework that will allow us to analyze the broader effects of antidumping law. 


\section{Econometric Model}

To quantify the magnitudes of the effects on imports and domestic output of the various stages of the suit-filing process, we characterize the joint distribution of $\boldsymbol{f}_{\boldsymbol{i}}, \boldsymbol{I M P} \boldsymbol{P}_{\boldsymbol{i}}^{*}$ and $\boldsymbol{O U} \boldsymbol{T}_{\boldsymbol{i}}^{*}$ with the same framework used to assess the impact of duties only. Now, however, the conditional mean functions for the industry-level imports and outputs include accumulated index variables similar to $O G D_{i t}$ for the other stages of the antidumping suit-filing process. We quantify the impacts of an antidumping suit petition and an affirmative preliminary LTFV determination. In addition, we attempt to quantify the differential impact on imports and domestic output depending on whether a suit ends in duties, suspension, or withdrawal. Suits ending in a negative determination are taken to have no lasting effect on subsequent imports and domestic output.

The conditional means of our industry-level output and import equations are based on the additional indicator variables $I_{g i t}^{k}(s),(k=O G P$, $O G P L F V, O G S U S$, and $O G W D$ ) that count, respectively, the number of ongoing antidumping petitions $(O G P)$, ongoing affirmative preliminary LTFV determinations (OGPLFV), ongoing suspended suits $(O G S U S)$, and ongoing withdrawn suits $(O G W D)$ for all $s \in(t, t+1)$ in product class $g$ in industry $i$ and time period $t$. The indicator variable $I_{\text {git }}^{O G P}(s)$ turns on at the filing date of the suit and remains on until the suit's final disposition date. The indicator variable $I_{g i t}^{O G P L F V}(s)$ remains on from the date of the affirmative preliminary LTFV decision until the suit's final disposition date. The final disposition of the suit is determined by one of the following four events: (1) a negative final determination, (2) the imposition of duties, (3) the suspension of the investigation, or (4) the withdrawal of the suit by the petitioner. Using those variables we can construct the integrated, industry-aggregate indexes of activity in each of these portions of the suit-filing process for year $t$. For the same reasons given earlier for $I_{g i t}^{O G D}(s)$, we maintain the assumption that $\theta_{i}$, industry $i$ 's unobserved filing propensity, is independent of $I_{g i t}^{k}(s)$ for the additional indicator variables $(k=O G P, O G P L F V$, $O G S U S$, and $O G W D$ ) as well.

In terms of this new notation the normalized conditional mean import and output functions become 


$$
\begin{aligned}
\mu_{i t}^{m}= & \beta^{m} \theta_{i}+\xi_{t}^{m}+\beta_{1}^{m} O G P_{i t} / G_{i t} \\
& +\beta_{2}^{m} O G P L F V_{i t} / G_{i t}+\beta_{3}^{m} O G S U S_{i t} / G_{i t} \\
& +\beta_{4}^{m} O G W D_{i t} / G_{i t}+\beta_{5}^{m} O G D_{i t} / G_{i t}
\end{aligned}
$$

and

$$
\begin{aligned}
\mu_{i t}^{o}= & \beta^{o} \theta_{i}+\xi_{t}^{o}+\beta_{1}^{o} O G P_{i t} / G_{i t} \\
& +\beta_{2}^{o} O G P L F V_{i t} / G_{i t}+\beta_{3}^{o} O G S U S_{i t} / G_{i t} \\
& +\beta_{4}^{o} O G W D_{i t} / G_{i t}+\beta_{5}^{o} O G D_{i t} / G_{i t}
\end{aligned}
$$

where

$$
\begin{aligned}
& O G P_{g i t}=\int_{t}^{t+1} I_{g i t}^{O G P}(s) d s, \operatorname{OGPLFV}_{g i t}=\int_{t}^{t+1} I_{g i t}^{O G P L F V}(s) d s, \\
& \operatorname{OGSUS}_{g i t}=\int_{t}^{t+1} I_{g i t}^{O G S U S}(s) d s, \text { and } \mathrm{OGWD}_{g i t}=\int_{t}^{t+1} I_{g i t}^{O G W D}(s) d s .
\end{aligned}
$$

Each of these four variables without the $g$ subscript given in equations 21 and 22 is the sum of that variable over the $G_{i t}$ TSUS products in industry $i$ for year $t$. The coefficients $\beta_{j}^{k},(j=1,2, \ldots, 5$ and $k=m, o)$ quantify the effect of a one unit change in these count variables on the rate of imports and output in industry $i$ during time period $t$. Assuming the same distribution for $\boldsymbol{\eta}_{i t}$ defined earlier, the likelihood function for this model is identical to the one given in equation 20 , except for the expanded set of regressors in the conditional mean function for the normalized level of imports and domestic output.

\section{Results}

The estimates of the parameters of the filing equation obtained from jointly estimating this equation with our expanded model for the conditional mean of imports and domestic output do not differ very much from the estimates in the first column of table 2 in terms of their signs and magnitudes or the precision with which they are estimated. Con- 
sequently, we omit these results and simply note that they are consistent with our interpretation of behavior for outcome filers. The elasticities of the expected number of filings with respect to changes in any of the four variables evaluated at the sample mean of the vector of regressors are: IMPEN, 0.455; CAPU, - 0.876; EMP, 0.376, and VADD/OUT, -1.66 .

The results in the second column of tables 3 and 4 shed some light on the importance of the nonduty impacts of antidumping law discussed earlier. In particular, the second column of table 3 shows fairly precisely estimated import effects for the stages of the investigation process included in our estimation. Consistent with the outcome filer interpretation of investigation effects, we find a slight acceleration of imports with the filing of an antidumping petition. The major reduction in the flow of imports occurs with the finding of a positive preliminary LTFV determination. This affirmative determination is predicted to reduce the annual flow of imports relative to the presuit base rate of imports by $\$ 25.36$ million $(33.81-8.45)$. If the petition is suspended, then the annual rate of imports under the suspension agreement is predicted to be $\$ 29.57$ million below the base rate. The imposition of duties predicts a similar reduction in the annual rate of imports ( $\$ 24.95$ million). A suit ending in withdrawal predicts no statistically significant change in the flow of imports relative to the base level flow of imports for that industry and time period. The output effects in the second column of table 4 are largely opposite in sign and smaller in absolute value, but less precisely estimated than those for the import equation. Together, these results are consistent with the view that temporary protection from imports and a proportionately smaller increase in domestic output is a typical outcome of an affirmative preliminary LTFV determination, even if the suit does not end in duties. The second column of table 5 reports the point estimate of this net effect (sum of imports and domestic output) obtained by adding analogous suit activity coefficients in the second column of tables 3 and 4 .

Figures 2 through 5 depict the import, output, and sum of imports and output effects of various hypothetical petitions according to our estimation results. The figures, which suggest the kind of import and output effects that might accompany an antidumping investigation, are constructed under the assumption that the preliminary LTFV determination occurs five months into the investigation, suspensions occur ten 
Table 5. Output and Import Net Effects

\begin{tabular}{|c|c|c|c|c|}
\hline \multirow[b]{2}{*}{ Variable } & \multicolumn{2}{|c|}{ Single-filing strategy models } & \multicolumn{2}{|c|}{ Two-filing strategy model } \\
\hline & $\begin{array}{c}\text { Duties-only } \\
\text { model }\end{array}$ & $\begin{array}{c}\text { Full } \\
\text { investigation } \\
\text { effects model }\end{array}$ & $\begin{array}{l}\text { Outcome- } \\
\text { filer } \\
\text { model }\end{array}$ & $\begin{array}{c}\text { Process-filer } \\
\text { model }\end{array}$ \\
\hline$O G P_{i t} / G_{i t}$ & $\ldots$ & $\begin{array}{c}1.15 \\
(0.85)\end{array}$ & $\begin{array}{c}9.33 \\
(6.14)\end{array}$ & $\begin{array}{r}-15.63 \\
(6.38)\end{array}$ \\
\hline$O G P L F V_{i r} / G_{i t}$ & $\ldots$ & $\begin{array}{c}-8.86 \\
(3.45)\end{array}$ & $\begin{array}{r}-38.85 \\
(15.37)\end{array}$ & $\begin{array}{c}0.45 \\
(3.29)\end{array}$ \\
\hline$O G S U S_{i r} / G_{i t}$ & . & $\begin{array}{c}-4.00 \\
(1.28)\end{array}$ & $\begin{array}{c}22.77 \\
(17.82)\end{array}$ & $\begin{array}{c}1.09 \\
(3.84)\end{array}$ \\
\hline$O G W D_{i r} / G_{i t}$ & $\ldots$ & $\begin{array}{c}-2.74 \\
(2.81)\end{array}$ & $\begin{array}{c}10.05 \\
(12.03)\end{array}$ & $\begin{array}{c}1.26 \\
(4.32)\end{array}$ \\
\hline$O G D_{i r} / G_{i t}$ & $\begin{array}{r}-3.42 \\
(1.02)\end{array}$ & $\begin{array}{c}-8.98 \\
(3.17)\end{array}$ & $\begin{array}{c}-9.14 \\
(4.36)\end{array}$ & $\begin{array}{r}-2.49 \\
(2.13)\end{array}$ \\
\hline
\end{tabular}

Source: Authors' calculations, sum of suit activity index coefficient estimates given in tables 3 and 4 . Standard errors are in parentheses.

months into the investigation, and final determinations occur at the end of the twelfth month of the investigation. These timing assumptions approximate the normal statutory limits imposed on the different phases of the investigation process. We use the coefficient estimates given in the second columns of tables 3,4 , and 5 to compute the cumulative impact on imports, output, and the sum of imports and domestic output. Because the coefficient estimates for $O G W D_{i t} / G_{i t}$ were never significantly different from zero, we do not use our point estimates to illustrate the effects of a withdrawn petition. All hypothetical petitions depicted in the figures are filed in the sixth month and, if they run the full course of the investigation, have a final determination one year later in the eighteenth month. All import and output effects are measured as deviations from zero.

Figure 2 depicts the case of an investigation that had an affirmative preliminary LTFV determination and resulted in the imposition of duties. According to our estimates in table 3, filing would lead imports to rise above their baseline until the date of preliminary LTFV determination (in this case, five months into the investigation), at which point imports would begin to fall. By the seventh month of the investigation, imports would have returned to their baseline level, and they would drop below baseline for the remaining five months of the investigation. Imposing duties at the end of twelve months then essentially continues the protection afforded during the last seven months of the investiga- 
Figure 2. Effects of an Antidumping Investigation on Imports and Domestic Output When a Petition Is Filed, the Preliminary LTFV Is Positive, and a Duty Is Imposed

Millions of 1972 dollars

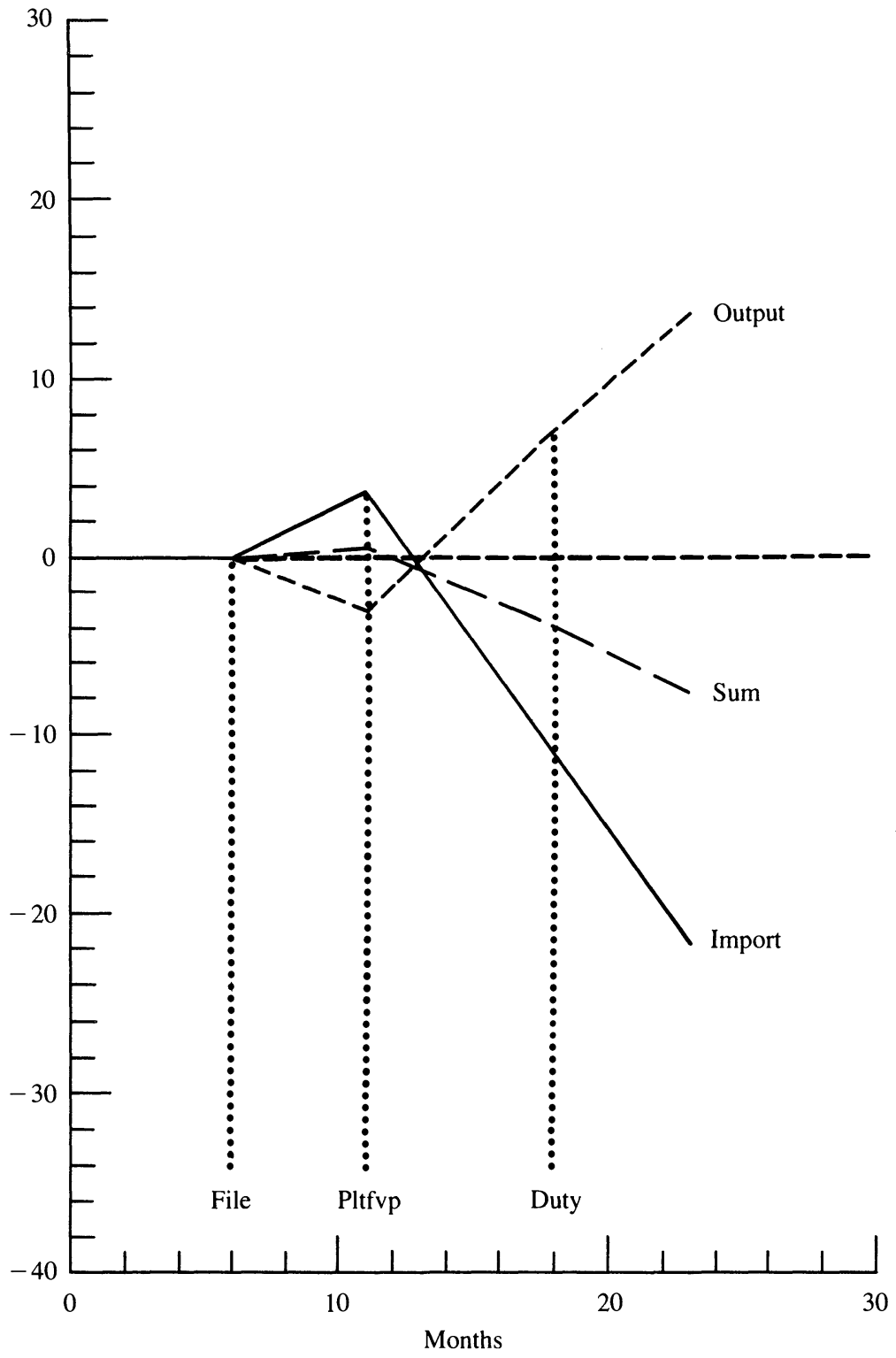

Source: Authors' calculations using the single-strategy model and assuming a positive preliminary less-than-fair-value determination (Pltfvp). 
tion. Thus, as figure 2 makes clear, our point estimates suggest that the investigation effects restrict trade from the date of an affirmative preliminary LTFV determination as if the expected antidumping duties were put in place on that date. Given that this accounts for a bit more than half of the statutory investigation period, and that the first five months of the investigation see a small rise in imports, we conclude that a petitioning firm can expect to receive roughly half the import relief during the period of investigation that it would have received if antidumping duties had been imposed from the date of filing. This conclusion is illustrated by comparing figure 3 , which depicts the import effects of a petition whose preliminary LTFV determination is affirmative but whose final determination is negative, with figure 4, which depicts the effect on the level of imports if an antidumping duty had been imposed on the date of filing. Figure 5 depicts the import effects of a suspension agreement. As noted above, our point estimates suggest that suspension agreements restrict imports at least as much as duties would. These same figures paint qualitatively the exact opposite picture with respect to domestic output.

For the sum of both imports and domestic output, figures 2-5 all show that, although domestic output is enhanced by the same stages of the suit resolution process that restrict imports and is restricted by those stages that enhance imports, the import effect, for most stages, dominates the domestic output effect. For example, in figure 2, the net effect of filing a petition is a slight acceleration in the sum of imports and domestic output, because the surge in imports is larger in absolute value than the drop in domestic output, although the standard error estimates in the second column of table 5 show that this net effect is imprecisely estimated. The net effects of both an affirmative preliminary LTFV decision and an actual duty are fairly precisely estimated to be negative, with the trade-restricting effect dominating the domestic outputenhancing effect in both cases. The net effect of a suspension agreement is also precisely estimated to be negative. Consequently, the net effect of the various stages of the suit resolution process and suit outcomes in figures 2-5 is a reduction in the sum of imports and domestic output. These net results are consistent with the view that the suit resolution process, the presence of suspension agreements, and the imposition of duties all result in net losses in domestic consumer welfare. 
Figure 3. Effects of an Antidumping Investigation on Imports and Domestic Output When a Petition Is Filed, the Preliminary LTFV Is Positive, and a Duty Is Not Imposed

Millions of 1972 dollars

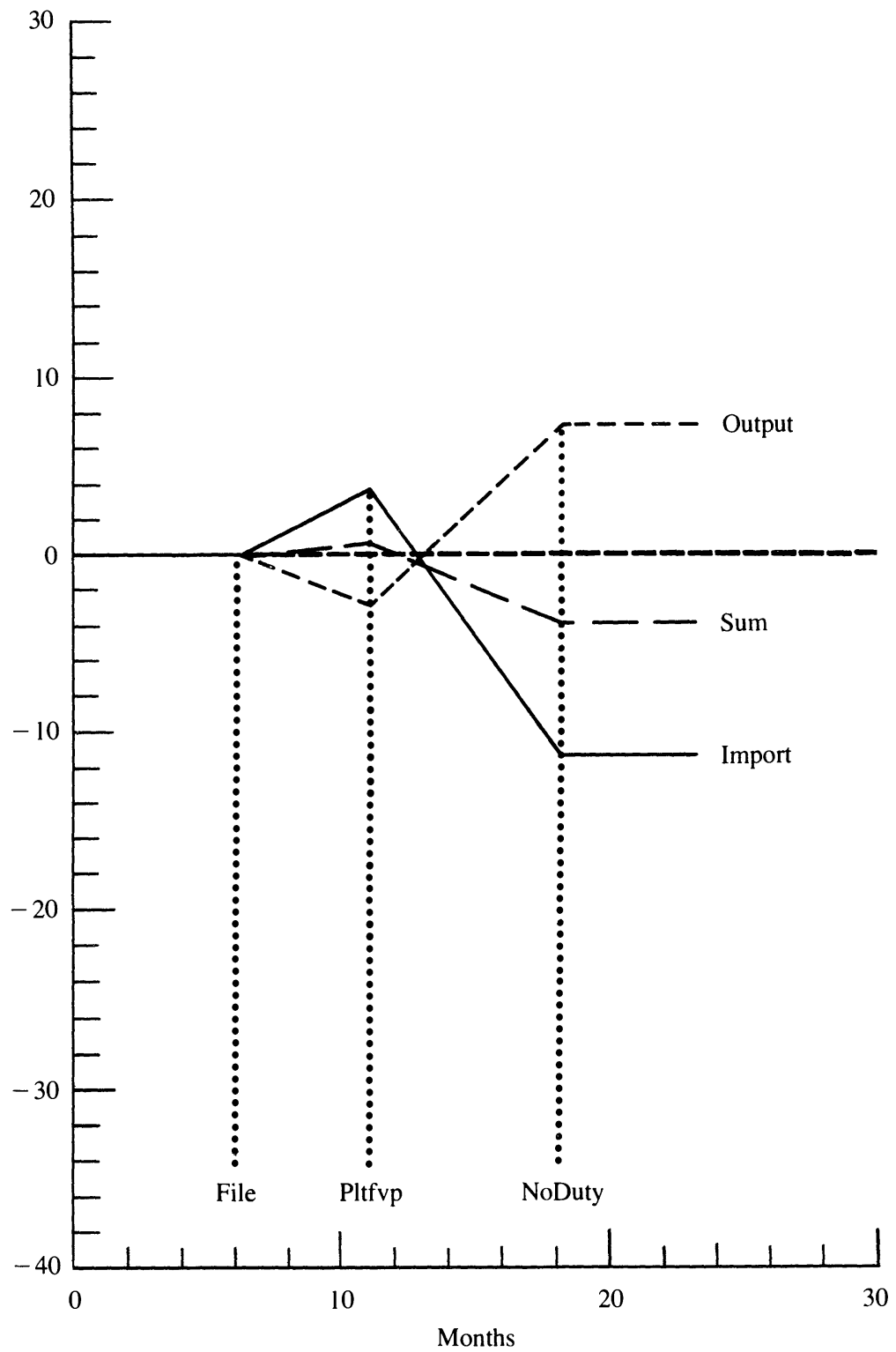

Source: Authors' calculations, using the single-strategy model and assuming a positive preliminary less-than-fair-value determination (Pltfvp). 
Figure 4. Effects on Imports and Domestic Output if an Antidumping Duty Had Been Imposed during the Investigation Period

Millions of 1972 dollars

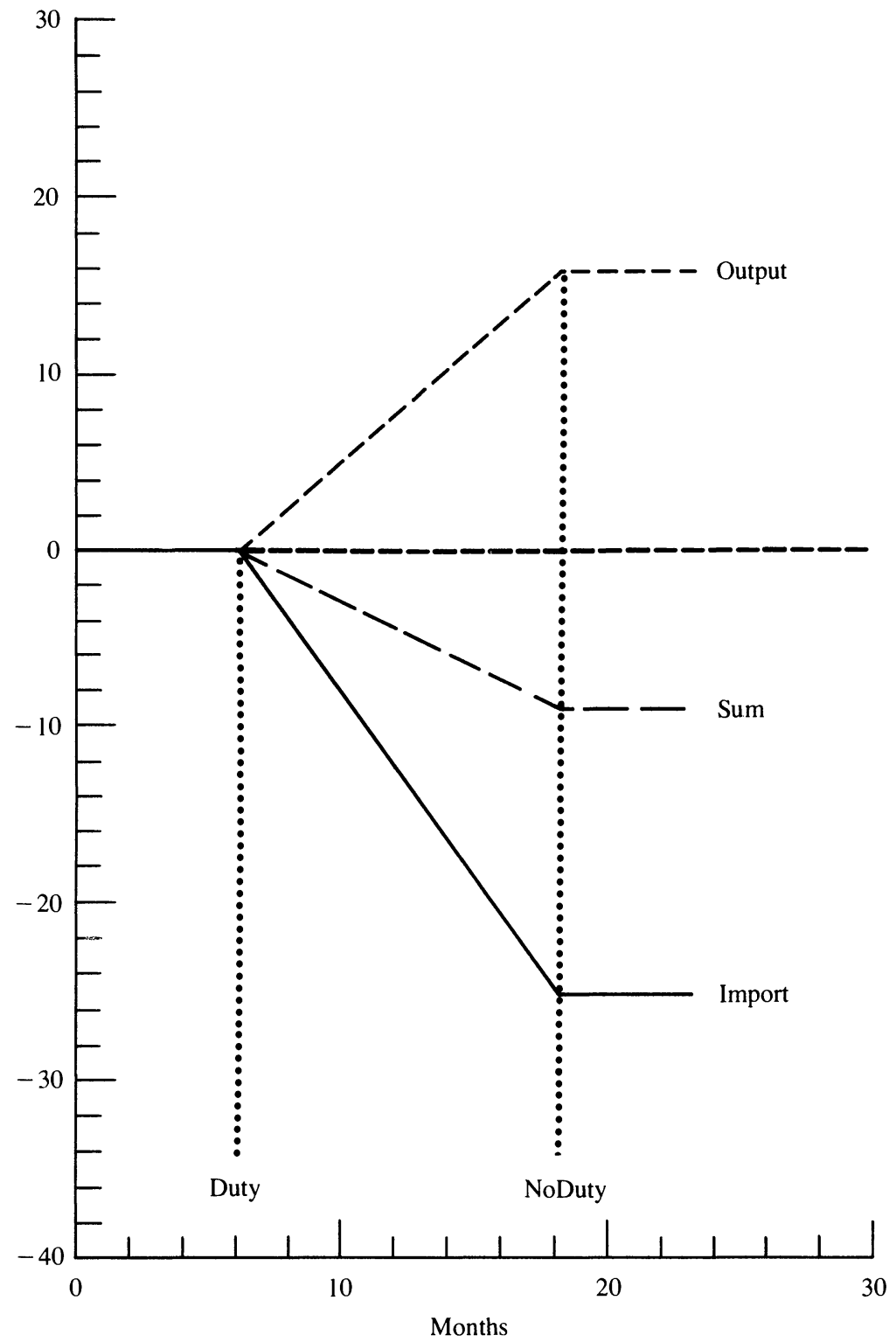


Figure 5. Effects of an Antidumping Investigation Suspended after a Positive Preliminary Less-than-Fair-Value Determination

Millions of 1972 dollars

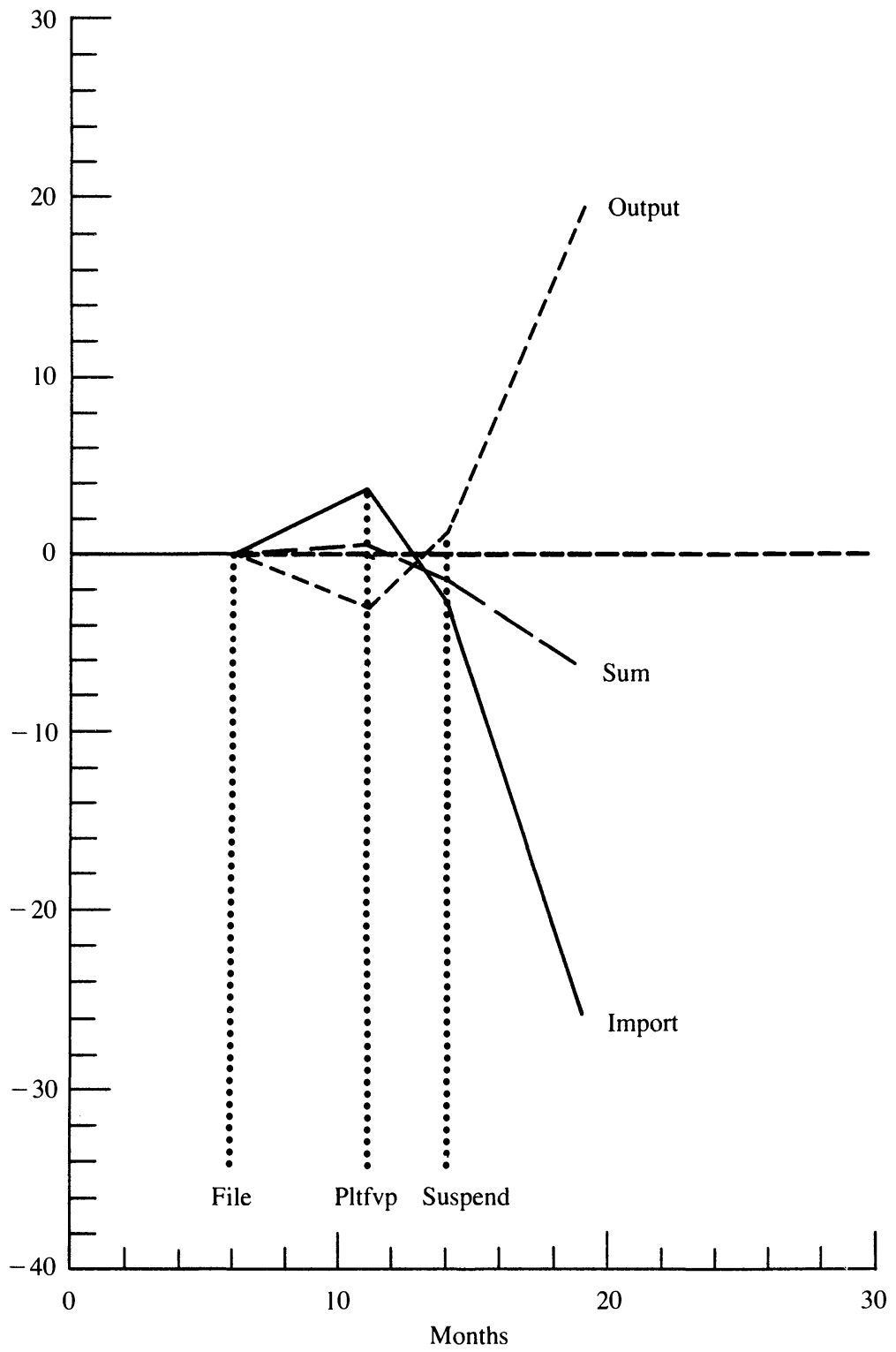

Source: Authors' calculations, based on the single-strategy model. 


\section{Investigation Effects with Both Process and Outcome Filers}

The results of the previous section appear to support the outcomefiling strategy over the process-filing strategy. One would expect the process-filing strategy to be far less common, however, and to be used primarily by those industries that are able to maintain "orderly competition" in their domestic market and that can agree (either through a strong industry association or small numbers) to file antidumping suits in periods of sufficiently low capacity utilization. We would expect that industries characterized by large numbers of firms without a strong industry association would find a process-filing strategy more difficult to pursue. Therefore, if this strategy is used by any industries in our sample, it is likely to be only a small number of them. Consequently, we would expect the outcome-filing effects to dominate in a model that does not simultaneously allow for the possibility of outcome and process filers.

In this section we examine whether it is possible to find evidence consistent with the use of the process-filing strategy by a subset of industries in our sample. Because the filing strategy used by a firm is unobservable, we must account for this possibility in our econometric model of filings, imports, and output. For the reasons just discussed, however, there are also observable variables that we believe should increase the probability that a given industry is using the process-filing strategy rather than the outcome-filing strategy.

Our general modeling approach specifies the filing strategy used by an industry for our entire sample time period as a latent indicator (0-1) random variable $y_{i}$, where $y_{i}=1$ if the industry uses the process-filing strategy and $y_{i}=0$ if it uses the outcome-filing strategy. The probability that $y_{i}$ takes on the value 1 is assumed to depend on observable and unobservable industry characteristics at the beginning of the sample period. Conditional on each one of these filing strategies, we hypothesize a distribution of filings, imports, and output for our sample period for each industry that embodies the restrictions on the mean function of industry-level filings implied by each of the filing strategies.

The unrestricted form of our two-strategy model allows for the existence of two separate joint distributions of filings, imports, and domestic output, conditional on the unobservable latent variable $y_{i}$. It places no restrictions on which variables enter the filing rate function 
for either strategy. It also places no restrictions on signs and relative magnitudes of the coefficients on the five indicator variables in the mean function for imports and domestic output for either strategy. Finally, our unrestricted model places no restrictions on how observable characteristics of the industry affect the probability that it is using either of the two filing strategies. If certain restrictions can be imposed on this unrestricted two-strategy model, then we can conclude that there is evidence for the simultaneous existence of both outcome and process filers.

The restrictions on our econometric model are guided by the theoretical results, discussed earlier, which imply that process filers decide to initiate antidumping suits based purely on the level of capacity utilization in their industry. Consequently, the filing rate function for the joint distribution of filings, imports, and output for the process-filing strategy should contain only capacity utilization. The theory gives no guidance concerning the dynamics of the effect of capacity utilization on filing. We included lags of capacity utilization up to the point where the null hypothesis of excluding further lags could not be rejected. This led to the inclusion of $C A P U_{i t-1}$ and $C A P U_{i t-2}$. From our earlier discussions, the filing rate function for outcome filers should contain all of the variables used to determine injury-IMPEN ${ }_{i t-1}, C A P U_{i t-1}$, $E M P_{i t-1}$, and $V A D D_{i t-1} / O U T_{i t-1}$. Although the same five indicator variables-OGP, OGPLFV, OGSUS, OGWD, and $O G D$-enter the mean functions for imports and output for both filing strategies, the coefficients associated with these variables should differ across the two filing strategies in the manner predicted in our discussion of the outcomeand process-filing strategies. Evidence consistent with the coexistence of outcome and process filers would be, first, that the restrictions on which variables enter into the process- and outcome-filing equations are not rejected by the data, and, second, that the sign restrictions on the coefficients associated with our five petition-stage variables are not rejected for the import and domestic output equations for both of the filing strategies.

Although the true filing strategy used by an industry is unobservable, the presence of several observable industry characteristics may increase the probability that it is using the process-filing strategy. We account for this by specifying the probability that an industry is using the process-filing strategy as a function of observable industry characteristics. 
Several of these characteristics are meant to reflect variation across industries in the cost of using antidumping law and to capture the notion that the process-filing strategy-whose benefits are relatively shortlived-is less likely to be chosen by industries with high filing costs. The first characteristic is the degree of unionization in the industry at the beginning of the sample period. All firms in an industry benefit from the protection provided by an antidumping suit, but only those firms filing the suit bear the costs. We expect more highly unionized industries to have higher probabilities of being process filers because a strong union presence in an industry provides an additional across-firm organization to assist in overcoming the coordination and cost-sharing problems associated with filing an antidumping suit on behalf of the industry. The second factor is the size of industry, which we measure by the level of employment at the beginning of the sample period. Because the fixed cost of filing an antidumping suit is substantial, a large industry can share these fixed costs over a greater number of firms and employees. That, in turn, means that fewer expected benefits per firm are necessary to trigger an antidumping suit petition, making process filing more likely. The final variable is the import penetration ratio at the beginning of the sample period. We expect larger values of this variable to be associated with higher probabilities of process filing, because, unless firms are faced with substantial import competition, imports are likely to have little effect on domestic output, and thus only a small benefit would come from reducing the flow of these imports. Consequently, the firms in the industry would have little incentive to pursue temporary protection through antidumping law.

\section{Econometric Model}

The econometric model that we use to estimate the effects of antidumping law on imports and output, while allowing for the possibility of both process and outcome filers, extends the basic econometric model of the joint distribution of filings, imports, and output. We will outline the additions to this framework necessary to construct the likelihood function in this case.

First, we specify a distribution for the filing strategy regime indicator $y_{i}$. In this case we hypothesize that

$$
\operatorname{pr}\left(y_{i}=1 \mid \theta_{i}\right)=\Phi\left(\mathbf{z}_{i}^{\prime} \boldsymbol{\alpha}+\rho \theta_{i}\right),
$$


where $\Phi(t)$ is the standard normal distribution function, $\mathbf{z}_{i}$ is a vector of observable industry characteristics at the beginning of the sample that predict the filing strategy used by an industry, and $\theta_{i}$ is the unobservable industry characteristic defined earlier, which also influences the filing strategy used by an industry.

The conditional mean of the filing rate for the outcome strategy is

$$
\begin{aligned}
\mu_{i t}^{f . O}= & \exp \left[\gamma_{1 t}+\gamma_{2}^{O} I M P E N_{i t-1}+\gamma_{3}^{o} C A P U_{i t-1}\right. \\
& \left.+\gamma_{4}^{o} E M P_{i t-1}+\gamma_{5}^{O}\left(V A D D_{i t-1} / O U T_{i t-1}\right)+\theta_{i}\right]
\end{aligned}
$$

where $\gamma_{1 t}$ denotes the set of fixed time effects. The conditional mean of the filing rate for the process strategy is

$$
\mu_{i t}^{f, P}=\exp \left(\gamma_{1 t}+\gamma_{2}^{P} C A P U_{i t-1}+\gamma_{3}^{P} C A P U_{i t-2}+\delta \theta_{i}\right)
$$

where $\delta$ is a parameter that accounts for how $\theta_{i}$ affects the filing rate under the process-filing strategy. Following the procedure to derive the density of $f_{i}$ given in equation 7 , one can derive the density of $f_{i}$ conditional on $y_{i}$ and $\theta_{i}$, by substituting the strategy-specific conditional mean function into $\operatorname{pr}\left(f_{i} \mid \theta_{i}\right)$. This yields $p r_{j}\left(f_{i} \mid \theta_{i}, y_{i}\right)$ for $j=O, P$, where $O$ is the outcome strategy and $P$ is the process strategy.

Let the conditional mean function for $I M P_{i t} / G_{i t}$ and $O U T_{i t} / G_{i t}$ for $O$ and $P$ be defined as

$$
\begin{aligned}
\mu_{i t}^{k, j}= & \beta^{k, j} \theta_{i}+\xi_{t}^{m}+\beta_{1}^{k, j} O G P_{i t} / G_{i t} \\
& +\beta_{2}^{k, j} O G P L F V_{i t} / G_{i t}+\beta_{3}^{k, j} O G S U S_{i t} / G_{i t} \\
& +\beta_{4}^{k, j} O G W D_{i t} / G_{i t}+\beta_{5}^{k, j} O G D_{i t} / G_{i t}
\end{aligned}
$$

where $k=m, o$ (for imports and output) and $j=O, P$ (for outcome and process filers), so that we allow for different $\beta_{i}$-coefficients for each filing regime. We assume that the disturbances to the conditional mean function for the process-filing regime $\left(\boldsymbol{\eta}_{i t}^{P}\right)$ and for the outcome-filing regime $\left(\boldsymbol{\eta}_{i t}^{\boldsymbol{o}}\right)$ each possess the $N\left(0, G_{i t}^{-1} \Sigma\right)$ distribution defined earlier. By substituting the process or outcome strategy conditional mean vector for imports and output into equation 18 , we can derive $h_{j}\left(\boldsymbol{I M P}_{i}^{*}\right.$, OUT $\left.\boldsymbol{T}_{i}^{*} \mid \theta_{i}, y_{i}\right)$, the density of imports and output conditional on $y_{i}$ (the filing strategy $j$ being followed by the industry) and $\theta_{i}$.

Following the logic used to derive the joint density of filings, imports, and output for the sample period given in equation 19 , we can 
derive this same joint distribution conditional on the filing regime and $\theta_{i}$. Let

$$
g_{j}\left(f_{i}, \text { IMP }_{i}^{*}, \mathrm{OUT}_{i}^{*} \mid \theta_{i}, y_{i}\right)=h_{j}\left(\operatorname{IMP}_{i}^{*}, \mathrm{OUT}_{i}^{*} \mid \theta_{i}, y_{i}\right) p r_{j}\left(f_{i} \mid \theta_{i}, y_{i}\right) .
$$

where $j=O$ or $P$. Then the density of $\left(\boldsymbol{f}_{i}, \boldsymbol{I M P} \boldsymbol{P}_{i}^{*}, \boldsymbol{O U} \boldsymbol{T}_{i}^{*}\right)$, conditional on $\theta_{i}$ only, can be derived by "integrating" with respect to the density of the indicator variable $y_{i}$ :

$$
\begin{aligned}
& g_{O, P}\left(f_{i}, \boldsymbol{I M P}_{i}^{*}, \boldsymbol{O U} \boldsymbol{T}_{i}^{*} \mid \theta_{i}\right)= \\
& g_{P}\left(f_{i}, I M P_{i}^{*}, \boldsymbol{O U T} \boldsymbol{T}_{i}^{*} \mid \theta_{i}, y_{i}=1\right) \phi\left(\mathbf{z}_{i}^{\prime} \boldsymbol{\alpha}+\rho \theta_{i}\right) \\
& +g_{o}\left(\boldsymbol{f}_{i}, \boldsymbol{I M P} \boldsymbol{P}_{i}^{*}, \boldsymbol{O U} \boldsymbol{T}_{i}^{*} \mid \boldsymbol{\theta}_{i}, y_{i}=0\right)\left[1-\phi\left(\mathbf{z}_{i}^{\prime} \boldsymbol{\alpha}+\boldsymbol{\rho} \boldsymbol{\theta}_{i}\right)\right] .
\end{aligned}
$$

To obtain the unconditional distribution of filings, imports, and output, we integrate with respect to the discrete factor approximation for $f(\theta)$ in the same manner as is done to derive equation 20 . This yields

$$
p_{O, P}\left(f_{i}, \operatorname{IMP}_{i}^{*}, \boldsymbol{O U} \boldsymbol{T}_{i}^{*}\right)=\sum_{k=1}^{K} \pi_{k} g_{o, P}\left(\boldsymbol{f}_{i}, \operatorname{IMP}_{i}^{*}, \boldsymbol{O U} \boldsymbol{T}_{i}^{*} \mid \theta_{k}\right)
$$

Taking the $\log$ of $p_{O, P}\left(f_{i}, \boldsymbol{I M P} \boldsymbol{P}_{i}^{*}, \boldsymbol{O U} \boldsymbol{T}_{i}^{*}\right)$ yields the likelihood function that we maximize to compute the estimates of the parameters of the three conditional mean functions for the two filing strategies and the parameters of the filing strategy probability function.

\section{Results}

Table 6 presents the coefficient estimates for equation 23 , the equation that determines the probability that an industry is following the process-filing stategy. Because we assume that $\operatorname{pr}\left(y_{i}=1\right)=\Phi\left(\mathbf{z}_{i}^{\prime} \boldsymbol{\alpha}+\right.$ $\theta_{i}$ ), the elements of $\boldsymbol{\alpha}$ have the same interpretation as those from a probit model. They are proportional to the increase in the probability of the event $y_{i}=1$ (the industry is a process filer) brought about by a one unit increase in the variable associated with that coefficient. Consequently, these estimates imply that an industry is more likely to be a process filer the greater the percentage of all workers in the industry that are unionized in 1979, the greater the level of industry-wide employment in 1979, and the greater the import penetration ratio for this industry in 1979. To provide magnitudes more amenable to interpretation, we compute for all 338 industries in our sample the average 
Table 6. Probability of Process-Filer Model

\begin{tabular}{lcc}
\hline Variable & $\begin{array}{c}\text { Coefficient estimate } \\
\text { (standard error) }\end{array}$ & $\begin{array}{c}\text { Sample average } \\
\text { probability elasticity } \\
\text { (standard error) }\end{array}$ \\
\hline UNION79 & 0.012 & 0.85 \\
EMP79 & $(0.006)$ & $(0.32)$ \\
IMPEN79 & 0.004 & 0.36 \\
& $(0.001)$ & $(0.05)$ \\
& 1.297 & 0.27 \\
\hline
\end{tabular}

Source: Authors' calculations, based on $\mathrm{N}=338$ industries.

percentage increase in the probability that industry $i$ is a process filer brought about by a one percent increase in that element of $\mathbf{z}_{i}$. These average probability elasticities are reported in the second column in table 6. For example, a one percent increase in the number of employees in the industry predicts a 0.36 percent average increase in the probability that the industry is a process filer.

The second and third columns of table 2 present the filing equation estimates for the outcome- and process-filing strategies. The outcomefiling results are consistent with the earlier two filing equation estimations. All of the variables enter in qualitatively the same manner as for the two models estimated above. The filing equation for the processfiling strategy excludes all variables except two lags of $C A P U$. The addition of the remaining three regressors, IMPEN, EMP, and VADD/ $O U T$, to this equation does not add any statistically significant explanatory power to the model (the likelihood ratio test does not reject the null hypothesis that these three coefficients are jointly zero), which lends some support to the presence of two distinct filing strategies.

The third and fourth columns of tables 3 and 4 present the import and output equations for the outcome- and process-filing strategies, respectively. For the outcome-filing strategy, the third column of tables 3 and 4 yields investigation effects similar to the effects estimated for the single-filing strategy import and output equations presented in the previous section. The major difference between these two sets of results is the slightly decreased estimated precision for the estimates in the third column of tables 3 and 4 . The results in the fourth column of tables 3 and 4 present a different story of the effects of antidumping 
suits on imports and output when firms follow the process-filing strategy. All of the investigation effects other than those associated with simply filing the suit are considerably smaller in absolute value and quite imprecisely estimated. The only investigation effect that seems present under the process-filing strategy is the effect from filing the petition. Under this strategy, the filing of an antidumping suit predicts an immediate reduction in the rate of imports and an increase in the rate of domestic output. The remaining stages of the process appear to have little effect on the rate of imports or domestic output. Even the impact of antidumping duties, although estimated to be trade restricting, is not very precisely estimated.

To provide a comparative view of the accumulated trade-restricting effects of these different filing strategies, we present figures depicting the estimated accumulated trade distortions from a hypothetical suit filing, analogous to figures 2 through 5. Figure 6 depicts the effect on the levels of imports, output, and the sum of imports and output for a petition that is filed by an outcome filer in month six and that is given an affirmative preliminary LTFV determination in month eleven and a negative final determination in month eighteen. Figure 7 depicts the import, output, and net import and output effect for the same investigation history except that the petition is filed by a process filer. As the figures depict, the striking difference in the pattern of import, output, and net response to the various phases of the investigation process across the two filing strategies is consistent with our interpretations of the two strategies.

The net effects on the sum of imports and domestic output for outcome filers, presented in column 3 of table 5, are consistent with those obtained for the single-filing strategy model. Although all but the $O G P L F V_{i t} / G_{i t}$ and $O G D_{i t} / G_{i t}$ net coefficients are essentially zero, these two coefficients indicate significant net import and output reductions from these stages of the suit resolution process under the outcome-filing strategy, and hence net domestic consumer welfare losses. The net results for process filers, presented in column 4 of table 5 , imply that the only nonzero net effect is the large $O G P_{i t} / G_{i t}$ effect. This effect indicates substantial net import and output reductions from the filing of a petition under the process-filing strategy. Consequently, the processfiling strategy also entails welfare losses to domestic consumers. More 
Figure 6. Effects of an Antidumping Investigation on Imports and Domestic Output When a Petition Is Initiated by an Outcome Filer, the Preliminary LTFV Is Positive, and a Duty Is Not Imposed.

Millions of 1972 dollars

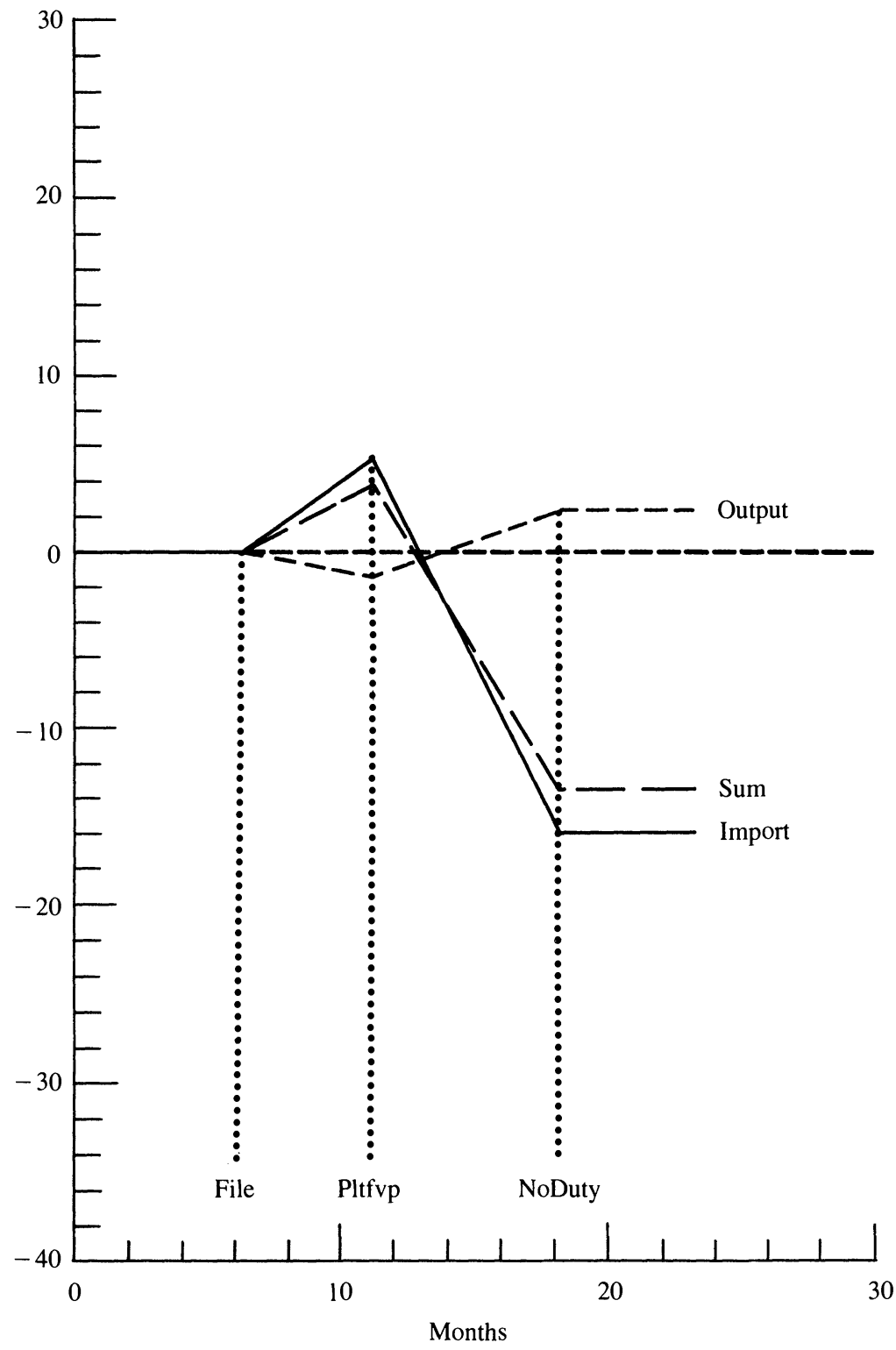


Figure 7. Effects of an Antidumping Investigation on Imports and Domestic Output When a Petition Is Initiated by a Process Filer, the Preliminary LTFV Is Positive, and a Duty Is Not Imposed.

Million of 1972 dollars

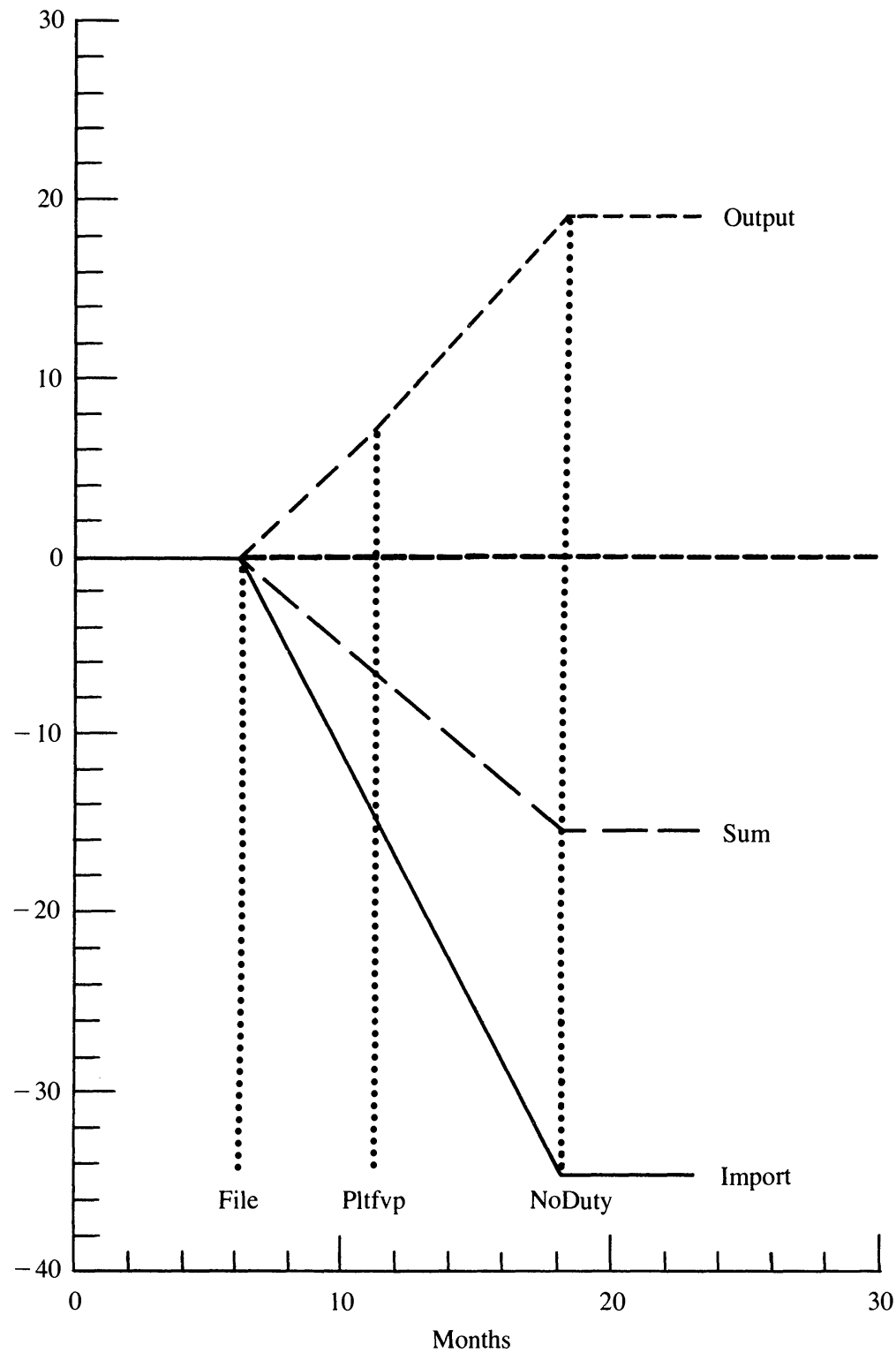

Source: Authors' calculations, based on the same investigation history as in figure 6 except that the petition is initiated by a process filer. 
important, these welfare losses result from an antidumping petition filed evidently only to secure the trade-restricting effects of the investigation alone.

Although the filing strategy pursued by a given industry is unobservable, our model does allow the computation of the probability that an industry is a process filer, given the estimated parameters of our econometric model and the vector $\mathbf{z}_{i}$ from the equation

$$
\operatorname{pr}\left(y_{i}=1 \mid z_{i}\right)=\sum_{k=1}^{K} \pi_{k} \Phi\left(\mathbf{z}_{i}^{\prime} \boldsymbol{\alpha}+\theta_{k}\right) .
$$

The sample average of these probabilities gives an estimate of the proportion of industries pursuing the process-filing strategy. For our parameter estimates, the sample average of the probability that an industry is a process filer is 3.5 percent. Assuming the validity of our two-strategy model, this implies that approximately 10 of the 338 industries in our sample are process filers. This finding is consistent with our initial view that most industries filing petitions under antidumping law are seeking the actual imposition of duties.

To investigate the implications of our two-strategy model, we computed the value of equation 30 for all observations in our sample and ranked each industry by its probability of being a process filer. The three industries with the highest probability of being process filers are: SIC 3312, blast furnaces, steelworks, and rolling mills; SIC 3714, motor vehicle parts and accessories; and SIC 3711, motor vehicles and passenger car bodies. Other notable industries among the ten with the highest probability of being process filers are SIC 3721, aircraft; and SIC 3662, radio and television transmitting, signaling, and detection equipment and apparatus. ${ }^{27}$ The probability that any of the remaining industries is a process filer falls rapidly from less than 10 percent to 0.7

27. Although we would like to caution that these probabilities are conditional on the validity of both our underlying process filer theory and our econometric model, anecdotal evidence seems to support the plausibility of these results. For example, concerning the filing behavior of the steel industry (the industry most likely, according to our results, to be a process filer), The Economist writes: "One lawyer who specializes in international trade says that, for a struggling mill, $\$ 400,000$ to bring an antidumping suit is money well spent, even without a final ruling; the process gums up the trade gears sufficiently to steer buyers-back to domestic steel." See "America's Steel Industry: Protection's Stepchild,'” The Economist, May 16, 1992, p. 98. 
percent. Consequently, all of the remaining industries have a very low estimated probability of following the process-filing strategy.

Finally, recall that, as we have defined them, outcome filers initiate suits primarily to obtain the protection that comes with a finding of dumping and the explicit remedies that follow (duties or suspension agreements). Conversely, process filers are interested primarily in the temporary protection afforded by the suit resolution process itself and do not file with the intent of eventually obtaining explicit remedies. Thus, a final implication is that the rate of duties per suit filed should be substantially lower for the process filers than for the outcome filers. To investigate this hypothesis we took the ten industries with the highest probability of being process filers, computed the sum of $O G D_{i t}$ for these industries for all six years in our sample, and then divided this sum by the sum of $f_{i t}$ for these same industries for all six years. This ratio gives the per-suit level of duty activity for this process filer sample. We repeated this same calculation for the remaining observations in our sample to obtain this ratio for our outcome-filer sample. Dividing the outcome-filer ratio by the process-filer ratio yields 5.5 , indicating that, for our sample, a product-level antidumping suit is five and one-half times more likely to end in duties for an outcome filer than for one of the ten highest probability process filers. This result is consistent with the view that process filers file less for the eventual protection provided by duties than do outcome filers.

\section{Conclusion}

In summary, we find strong evidence that antidumping law affects imports and import-competing domestic output in important ways other than through the imposition of duties. In particular, we find that suspension agreements lead to outcomes that are comparable in their restrictiveness to the imposition of antidumping duties. Moreover, important investigation effects appear to be associated with antidumping petitions: petitioning firms may enjoy import relief during the investigation period that amounts to about half of what they might expect from a positive final determination and duty imposition. We also find evidence of two kinds of filing strategies: outcome filers that seek the actual imposition of duties, and process filers that seek the trade-restric- 
tive effects of the investigation process alone. Finally, we find little evidence that withdrawn petitions lead to restricted trade.

To provide some idea of the magnitude of these effects, we used our single-strategy parameter estimates, given in the second column of tables 3 and 4 , to make some rough calculations of the trade-distorting effects of all of the antidumping suits that occur during our sample period. The total sample distortions to imports and output from the investigation process are computed as follows:

$$
\begin{aligned}
& D_{I N V}^{m}=\sum_{i=1}^{N} \sum_{t=1}^{T} \beta_{1}^{m} O G P_{i t}+\beta_{2}^{m} O G P L F V_{i t} \text { and } \\
& D_{I N V}^{o}=\sum_{i=1}^{N} \sum_{t=1}^{T} \beta_{1}^{o} O G P_{i t}+\beta_{2}^{o} O G P L F V_{i t} .
\end{aligned}
$$

The entire sample distortions to imports and output from the postinvestigation effects are computed as follows:

$$
\begin{aligned}
& D_{E N D}^{m}=\sum_{i=1}^{N} \sum_{t=1}^{T} \beta_{3}^{m} O G S U S_{i t}+\beta_{5}^{m} O G D_{i t} \text { and } \\
& D_{E N D}^{o}=\sum_{i=1}^{N} \sum_{t=1}^{T} \beta_{3}^{o} O G S U S_{i t}+\beta_{5}^{o} O G D_{i t} .
\end{aligned}
$$

We exclude the effects of withdrawn suits because the coefficients associated with $O G W D_{i t} / G_{i t}$ in both the import and output equations are never statistically different from zero. We then compute IMPTOT and OUTTOT, which are the sum of total imports and output over all industries and years in our sample, and express $D_{I N V}^{m}$ and $D_{E N D}^{m}$ as a percentage of IMPTOT, and $D_{I N V}^{o}$ and $D_{E N D}^{o}$ as a percentage of OUTTOT. For our sample of industries for the six years of available data, the total amount of import reductions from all investigation effects is approximately -0.26 percent of total imports over the sample period. The total distortions attributable to postinvestigation effects is -4.37 percent of total imports. Both the total investigation and postinvestigation effects are a very small percentage of OUTTOT, 0.0008 percent and 0.42 percent, respectively. To obtain the net import and output effects for our sample period, we compute both $D_{I N V}^{m}+D_{I N V}^{o}$ and $D_{E N D}^{m}+D_{E N D}^{o}$ as percentages of OUTTOT + IMPTOT. The investigation and postinves- 
tigation net distortions percentages are -0.03 and -0.14 , respectively.

An obvious question is why more industries do not file antidumping suits to take advantage of the investigation effects. Two factors work against more industries pursuing this form of protection. The first has to do with the design of antidumping law. Suits must either be filed by an interested party on behalf of the industry or be initiated by the ITA. Although the interested party is usually an industry association or a large fraction of firms in the industry, a cost is still associated with organizing and coordinating the necessary action to file a suit. The second factor is the explicit economic cost of hiring the legal and administrative expertise necessary to file an antidumping suit. This cost can easily amount to $\$ 500,000$ or more, and the protection provided, assuming neither duties nor a suspension agreement is eventually imposed, lasts roughly a year. For filing to be rational, then, the expected annual benefits to the petitioning party should at least exceed these costs. This circumstance does not seem likely for most of the industries in our sample. 


\section{Comments \\ and Discussion}

Comment by Robert E. Litan: Staiger and Wolak are to be commended for tackling an issue-the effects of the U.S. antidumping law-that for too long has not been taken seriously by many mainstream economists. For decades the dominant focus of trade specialists has been on the conventional instruments of trade protection, or tariffs, quotas, and quota look-alikes such as "voluntary" export restraints. Fortunately, economists have developed radar for detecting and measuring these forms of naked protection. And in some small way, even some arms of the government pay attention. A recent report by the International Trade Commission (ITC), for example, reported that tariffs and quotas on a wide range of products are costing consumers nearly $\$ 20$ billion a year.

But while most trade economists and many policymakers have been carefully watching out for the intercontinental missiles and bombers of trade protection-tariffs and quotas-they have ignored the damage caused by the cruise missiles of protection-the antidumping and countervailing duty laws that, by flying low to the ground, have escaped detection as protection by the conventional radar systems. It is easy, of course, to explain why many legislators have not attacked the protectionist effects of the unfair trade practice laws; by labeling them as means to root out "unfair practices,' Congress has effectively put them off limits. What legislator, after all, wants to be known for watering down laws designed to ensure "fair trade"?

The views expressed here are solely those of the author and should not be attributed to either the Department of Justice or the Clinton administration. 
It is more difficult to explain why the effects of these laws have escaped the attention of many mainstream economists, however. One possible reason is that the cumbersome mechanics of the laws seem too technical and thus too dirty for many economists to touch. Another possibility is that some of the mechanics are so outrageous that few economists can believe that policymakers pay serious attention to them.

Let me give a few examples. As Staiger and Wolak explain, the antidumping law has two stages. First, the Department of Commerce determines if dumping exists and, if so, how much; and second, if the resulting "margins" are positive, then the International Trade Commission determines whether they have been a cause of "material injury', to competing domestic products.

Take the determinations of dumping first. The law says that dumping exists if there is price discrimination by the foreign exporter, but, that in measuring price discrimination, Commerce must generally ignore sales in the home market that are below the average cost of production. If too few home market sales are left to make a meaningful comparison with sales to the United States, the Commerce Department must compare all U.S. sales to "constructed value," or average cost plus an 18 percent markup for overhead and profit.

Now what serious economist believes any of this makes sense? Domestic firms frequently sell below average cost of production, but few courts in this country would hold them in violation of our domestic antitrust laws unless they also sell below average variable cost. Moreover, how many domestic firms sell their goods at or above 118 percent of the average cost of production? Yet by requiring foreign firms to adhere to such behavior when demand is weak-and prices are thus below average cost-we come close to giving trade protection to competing domestic producers.

Or take the Commerce Department's practice of comparing an average foreign price or cost with the price of each and every U.S. sale of the foreign product and then throwing out all those comparisons that show U.S. prices to be higher than those made abroad. Put differently, Commerce generally refuses to make comparisons of average prices in the two markets. By doing so, it penalizes price variations by foreign producers. Yet now that the Robinson-Patman Act is pretty much a dead letter, we do not punish the same practices by domestic producers.

Finally, let's turn to methods the ITC uses to determine, in the 
language of the statute, whether the domestic producers have suffered " "material injury" by "reason of' the dumped imports. You would think that the law would require a "but for" analysis; namely, how much better off would the domestic industry have been but for the dumping found by Commerce? If the counterfactual improvement would have been above some minimum threshold, then the injury finding should be affirmative.

With the exception of a few commissioners, however, appointees to the ITC through the years have used any number of other methodsand I use the term generously - to make their injury determinations, even though ITC staff economists have developed a sophisticated, yet easy-to-use, comparative statics computer program to make the "but for' injury calculation. The net result, as the Staiger and Wolak empirical results confirm, is that the ITC tends to grant dumping relief when the domestic industry is performing poorly by some objective criterion, whether or not the dumping makes a significant contribution to that condition. By the same token, the ITC tends not to grant relief to domestic industries that may be healthy but that would nevertheless be doing much better in the absence of the unfair foreign practices.

In short, the structure and administration of the unfair trade practice laws-and principally the dumping law-are riddled with economic nonsense. This is true, by the way, not only in the United States, but elsewhere in the world. Indeed, where once only the United States, the European Community, Canada, and Australia were vigorous practitioners of antidumping voodoo, in recent years other countries such as Mexico and South Korea have been learning the art. I fear that dumping law and practice may be one of our growing exports.

Unfortunately, however, economists have made virtually no attempts to estimate the damage that our dumping law causes. Staiger and Wolak are to be commended for helping to fill this gap. Their most important contributions are to provide a sophisticated approach to modeling both the decision to file an unfair trade complaint and to estimating the effects of complaints that are filed, whether or not they are carried through to the ultimate conclusion. Indeed, one of the authors' main points is that dumping cases cause harm not only when they result in affirmative findings, but also merely upon being investigated or suspended. Based on their findings, Staiger and Wolak recommended at the Brookings conference that Congress lengthen the period that Com- 
merce is allowed for making preliminary dumping determinations, which, they argued, would improve the accuracy of the dumping margins and thus reduce the net protectionist effects. In this, the authors are probably right: the empirical work I have seen suggests that when Commerce relies on the best information available, or essentially the petitioners' data, it tends to find higher dumping margins than when it is able to audit the respondents' own data.

That's the good news. The bad news is that tinkering with dumping procedure or administration can bring only limited relief. The damage caused by the dumping law overwhelmingly results from its substance, namely, the way dumping must be measured and the way injury is typically determined.

In fact, for this reason it would have been desirable-had the authors had the data-for them to have included in their regressions not just the presence of a dumping investigation or finding (reflected in a dummy variable), but also the size of the margin, alleged or established. Clearly, the larger the margin, the greater the negative impact. The authors' equations instead measure only the average effect of a dumping investigation or finding and thus do not indicate how the effect varies with the size of the margin.

On the whole, however, the estimates confirm what most knowledgeable observers would have expected: that the filing of a dumping case is more likely for troubled industries than for those doing well; that, after an initial postfiling boost to imports, affirmative antidumping findings eventually suppress imports while benefiting the output of import-competing industries; and that suspensions of investigations lead to effects comparable to those of affirmative antidumping findings. What is needed in the future is for policymakers to be educated about the pernicious anomalies in the dumping law that cause unnecessary harm to domestic consumers and foreign exporters alike.

Comment by Michael L. Katz: Robert Staiger and Frank Wolak are to be commended for undertaking an ambitious project. In this paper they tackle a complex set of institutional factors, wade through a variety of theoretical hypotheses, and emerge with a sensible set of econometric estimates for some economically interesting values. The authors also are to be commended for responding to the comments and suggestions made at the time that they orally presented an earlier draft of this paper. 
In my comments here, I will touch on a few points where I believe that one could go further in addressing some of the earlier concerns.

The objective of the paper is to provide "estimates of the trade impacts of U.S. antidumping law and the determinants of suit-filing activity from 1980 to 1985 .' The authors jointly model the filing decision and the effects of various intermediate stages in the dumping complaint process on both domestic and foreign output choices. Particular attention is paid to the domestic producers' decision calculus about whether to file an antidumping suit.

The econometric model accounts for the fact that an antidumping suit may affect the behavior of foreign firms through a variety of different mechanisms. In particular the authors model investigation effects and what might collectively be labeled outcome effects. Investigation effects derive from the fact that the behavior of foreign firms during the investigation period can affect both the likelihood of sanctions' being imposed and the size of those sanctions. For example, if positive final determinations of injury and dumping follow a preliminary finding of dumping, then antidumping duties are applied to sales made during the investigation period, and these duties fall on the importers of the products. Thus foreign producers have incentives to reduce their output and raise their prices during an investigation. Outcome effects are those effects that arise after the conclusion of the investigation, and they can arise in several ways. Most obviously, antidumping duties may be imposed, raising the marginal costs of foreign competitors. As the authors correctly emphasize, this is not the only way to obtain a reduction in the strength of foreign competition. Suspension agreements can be negotiated with the International Trade Administration, whereby foreign firms change their behavior in return for a halt in the investigation. Or foreign and domestic producers may reach some informal agreement that results in withdrawal of a complaint.

Domestic producers may be motivated to file dumping complaints to obtain the private benefits of any of these effects. A central piece of the analysis concerns the distinction between outcome filers and process filers. Roughly speaking, outcome filers are firms that file suit in anticipation of obtaining a finding of dumping and some form of relief, either antidumping duties or a settlement agreement. Process filers are firms that file suits not to obtain a dumping finding, but rather to obtain the effects that arise solely from the investigation process itself. 
Staiger and Wolak note that a process-filing strategy is worth economists' and policymakers' attention as a distinct strategy only if two conditions are satisfied. First, it must be possible to obtain an investigation even if there is little chance of obtaining a finding of dumping on the merits of the case. The authors assure us that it is all too possible. Second, there must be significant competitive effects that are not dependent on a dumping finding. It is not immediately apparent that investigation effects could occur in the absence of a potential finding of dumping. Put another way, if no one expects the suit to succeed, then why should it affect their behavior? As the authors explain, there are two logical possibilities. One explanation builds on the work of Prusa and posits the existence of significant withdrawal effects. ${ }^{1}$ Such effects could arise even in the absence of a credible threat of an affirmative finding because the investigation process allows producers to invoke the Noerr-Pennington doctrine, which allows producers to collude more effectively. Once the agreement has been reached, the complaint is dropped. The econometric analysis, however, suggests that such withdrawal effects are not of practical importance. The alternative mechanism is that, during the time of the investigation, competitive behavior by foreign producers will increase the likelihood of a finding of injury. Consequently, the authors argue, even when an otherwise meritless complaint is filed, foreign output will fall during the investigation period.

This claim raises two questions. First, why not file such complaints all of the time? Implicit in the analysis is the notion that suits are too costly relative to the benefits during periods when the industry would otherwise successfully collude. To the extent that filing a complaint is a substitute for other forms of tacit collusion, an interesting line of inquiry would be to focus on understanding filing behavior in terms of the producers' ability to collude. In the paper Staiger and Wolak focus on the level of capacity utilization as one measure, but oligopoly theory suggests a variety of other structural conditions that might help explain the pattern of filing activity across industries, if not over time.

A second, closely related question takes the opposite tack: why is there any need to file a complaint at all? As Staiger and Wolak note, in at least some circumstances the threat of domestic firms' filing a dump- 
ing complaint might be enough to limit the competitive behavior of foreign firms. This question "why file at all" is particularly salient for process filers, who rely on the threat of sanctions, rather than their actual imposition, to restrict the behavior of foreign rivals.

The answer to this question is of interest for at least two reasons. First, the possibility of deterrence through the mere threat of a suit implies that the estimates obtained in the present paper based on the observed distortions that result when suits actually are filed may significantly underestimate the overall effects of the U.S. antidumping law. Second, a perspective that recognizes the potential importance of threats also redirects the types of questions asked about the determinants of suit activity. When one looks at the determinants of filing, for example, it is not obvious that the variables used to determine injury in an antidumping suit proceeding should be the central determinants of suit activity. Again, the question is what variables explain why it is necessary actually to carry out the suit. One might even find a U-shaped relationship (this is, after all, economics) for process filers. The logic is as follows. Where the benefits of bringing a suit are very low, no suits will be filed. And where the benefits are very high, there is no need actually to file because the threat will be credible. In an intermediate range, however, actual filing might be necessary to make the threat credible, given the foreign firms' uncertainty about the domestic firms' incentives to file. With this perspective the analysis focuses on conditions under which the threat of filing is not credible, yet the domestic producers do in fact have incentives to file.

In addition to raising additional questions about the domestic industry, this perspective also raises questions about the behavior of foreign producers. I would have liked to have seen more done to model foreign producers, and it seems that there might be some testable hypotheses here. If the foreign firms themselves are a tightly knit oligopoly, then they might be expected to be able to respond to the threat of an antidumping suit by tacitly colluding to reduce their output. Conversely, when there are many foreign firms, we would expect such collusion to break down, and the domestic industry would have to rely on the actual imposition of duties or a settlement agreement to obtain the desired constraint on competition. Thus one might examine the structure of the foreign component of the industry as an explanation of the suit-filing behavior of domestic firms. By embedding the filing decision in a 
broader game between foreign and domestic producers, one raises new questions and might obtain new answers.

Having exercised the discussant's prerogative of calling for still more to be done, let me close by again commending the authors for their work. Although I have suggested further directions in which they might take this research, the additional distance to be covered is short compared with the distance they have already come.

Comment by Leonard Waverman: My comments on this paper signify the costs of coming early to Brookings. I was wandering through the halls the day before the meeting, and Cliff Winston said, "What are you doing tonight?', I thought that was going to be an invitation for dinner. It was an invitation to read this paper. Fortunately, it is an excellent paper with new, important results.

The paper examines antidumping and filing rates on a four-digit SIC code basis. Using industry data creates several problems. The first one is that it is firms, not industries, that file antidumping cases, and in many cases firms file across a multiple of products. For example, U.S. firms filed twenty-seven antidumping cases against Canadian products from 1984 to 1993 (and forty-four Canadian actions were filed against U.S. firms). Twelve of these U.S. actions were in the steel industry but in five different four-digit SIC code industries. Most of these cases have been filed by one or two firms, so there are multiproduct firms that are filing cases across the four-digit industries used in Staiger and Wolak's analysis. Although the authors use a fixed effects term to pick up specific industry effects, I think these industry effects are going to be correlated across product groupings where the cases are initiated by multiproduct firms.

Second I think there is clearly a relationship over time in cases filed. The authors use a time dummy variable in the fixed effects model that is industry specific. Fixed time effects are of two kinds, however. Either a firm files a case, wins, and says, "I am successful and my competitors learn forever and never come back," or it is like firms in the steel industry (and the battery ad) and keeps coming and coming and coming. Thus a case with no time trend may signify more success than the fixedeffects model allows. Finally, whether refiling occurs in an industry is clearly endogenous; a fixed-effects time trend simply allows for exogenous industry learning, learning that is in reality endogenous. 


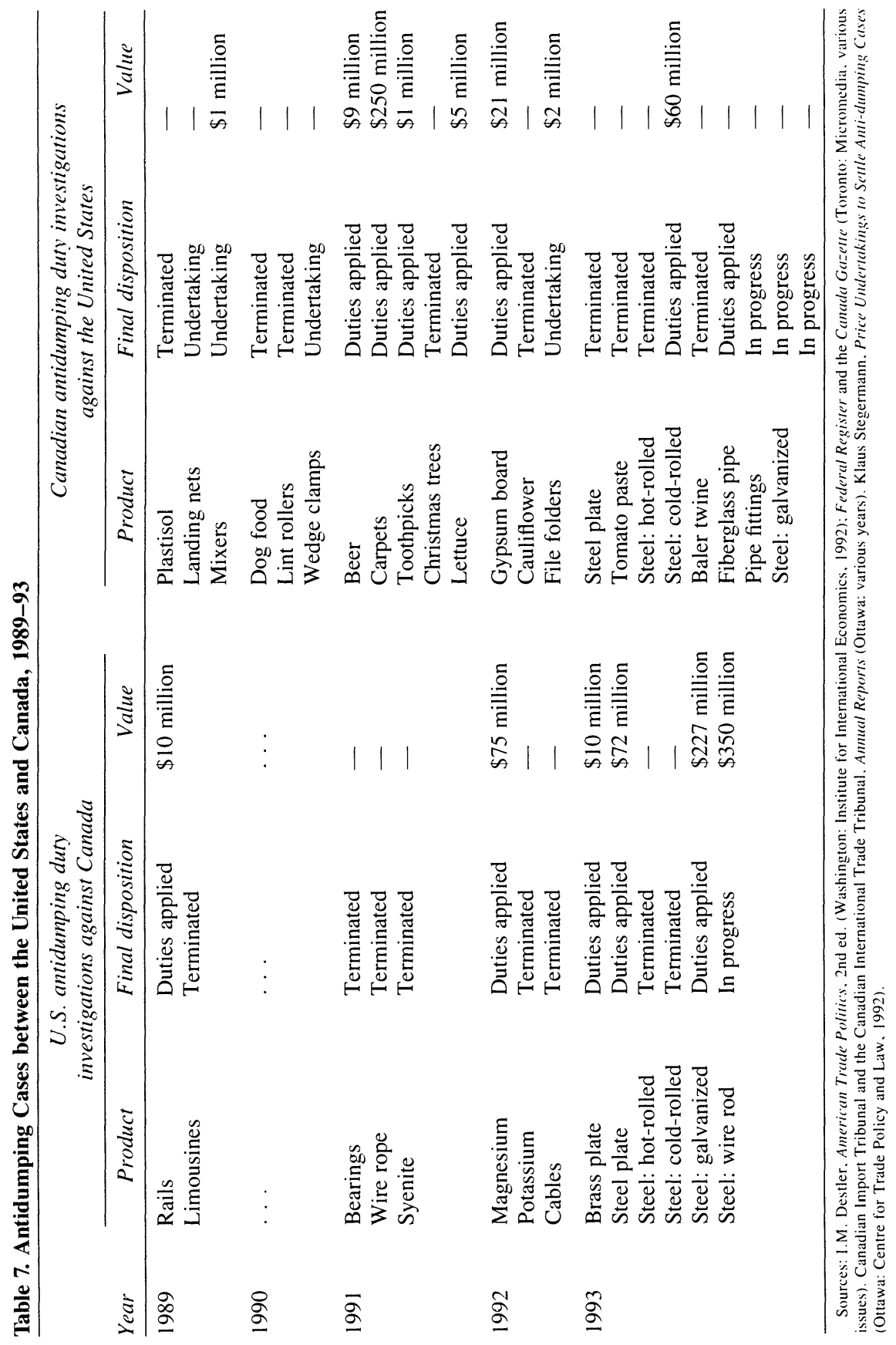


The coefficient that measures the impact of a duty on imports and domestic output is assumed to be the same across all products and industries. This assumption has two problems associated with it. First, the coefficient should depend on elasticities of demand and supply and the conditions of competition and so on. It is a much more complicated model than the complex one already run. Second, I agree with Bob Litan that the parameter measures whether a duty is levied or not and the coefficient is the amount in dollars or the change in output resulting from a successful action averaged across all industries. The reduction in imports so calculated is $\$ 25$ million 1972 dollars. It matters a great deal whether that $\$ 25$ million change in imports is in the automobile or raspberry industry $-\$ 25$ million is not a large percentage of domestic shipments in the former but is huge in the latter.

One issue that is not examined in the paper is retaliation. The possibility of retaliation suggests that the paper overestimates the gains to a U.S. industry from antidumping actions.

Table 7 shows the number of antidumping cases between Canada and the United States for the five years since the Canada-U.S. free trade agreement came into effect. Canadian firms have brought more antidumping cases against U.S. firms than U.S. firms have brought against Canada. In 1993 one can see the beginnings of a tit-for-tat strategy. In that year U.S. steel firms filed a whole host of steel cases against several firms, including those in Canada. Canadian firms retaliated in all the same products, except for wire rod, and that suit may be coming. In these cases exactly the same products in both countries are involved in cross-border antidumping actions. Retaliation reduces domestic output. For example, in cold-rolled steel, the United States (which began the process) terminated its procedure, while Canada found this year that the U.S. firms were engaged in dumping. Therefore, by not examining exports but concentrating on domestic production and imports, the authors may be overestimating the domestic gains from antidumping levies if exports are affected when there is retaliation.

Could one explain antidumping cases as examples of rent shifting? That is, are these actions levied on commodities produced in oligopolistic industries where profits could be shifted from foreign to domestic firms? If one examines the products involved in U.S.-Canadian crossborder actions-dog food, lint rollers, bearings, brass plate and steel products-there is not likely much rent shifting. We may be seeing 
antidumping actions in dying industries. Antidumping cases are not a good example of strategic trade theory; these are not the industries where huge dynamic scale effects exist that the new trade theory suggests to protect.

General Discussion: Robert Crandall noted that recent antidumping suits brought by U.S. steelmakers against foreign producers in several countries have been very expensive. Arguing that steel is a highly competitive industry, that domestic manufacturers have not brought such suits against all foreign competitors, and that these suits are likely to yield mixed results where duties are imposed against certain countries but not others, Crandall suggested that antidumping duties on steel would have a much greater effect on the source of steel imports than on their level. In addition, he asserted that the high level of product differentiation characteristic of the steel industry allows foreign producers to alter their products slightly in order to skirt antidumping duties altogether. Thus, Crandall contended, these dumping suits may not have the effects on domestic prices that U.S. manufacturers would hope they do and, consequently, they may simply be a costly - and unwiseinvestment for these firms. The one exception, Crandall said, might be the auto industry. Because of the concentration of production in that industry, the mere threat of dumping suits against foreign producers is likely to yield sizable benefits for domestic automakers. He argued that part of the sharp rise in Japanese auto prices not attributable to the increasing value of the yen could be traced to this threat.

Richard Schmalensee argued that the apparent benefits to domestic producers from filing antidumping suits ultimately leads to the question why all firms do not choose to file them. He suggested that highly concentrated industries and others that are well organized are probably the most likely to file antidumping suits, especially those suits seeking the process value of filing, because these industries can most easily overcome free-rider problems. At the same time, he conceded that some suits are filed in clearly competitive industries.

Martin Baily noted that, according to "old" trade theory, there are static efficiency gains for U.S. industries from international trade, while "new" trade theory assumes a world with learning by doing, or increasing returns, where protection allows companies to lower costs by moving down the learning curve. Baily posited a "new new" trade 
theory, in which increased international competition produces dynamic efficiency gains. He suggested that established firms often fail to adopt process and product innovations and changes in the techniques of production. International trade, Baily argued, forces a domestic industry to make such changes. According to his own empirical work, substantial productivity benefits accrue from increased competitive pressure. Baily surmised that antidumping statutes provide a lifeline to those firms that do not want to make innovations. Over the long run, such firms may be worse off, eventually being forced to make greater adjustments than they would have made in the short run had they changed and adapted more quickly.

Several participants commented on data, measurement, and modeling issues. Schmalensee questioned the authors' use of the ratio of value added to output as a measure of productivity. This variable, as he understood its construction, is simply a measure of vertical integration. Crandall noted that the authors measure the change in imports affected by an antidumping suit by using the level of imports at the time the suit was filed as the initial value. Arguing that foreign producers may know that a domestic firm intends to bring an antidumping suit (perhaps because of the firm's need to retain legal counsel), Crandall suggested that imports might increase in anticipation of the suit. In such cases, part of the drop in imports after a suit is filed may simply reflect a return to more normal levels. Peter Reiss suggested that the authors' $\theta$ variable, defined as the unobservable characteristic of a given industry that affects its rate of filing dumping petitions, should be treated as an economic parameter rather than as a nuisance parameter. Frank Wolak agreed with Reiss, adding that $\theta$ values can be used to recover estimates of the extent to which firms in a given industry are predisposed to select one of the two filing strategies described in the paper.

Robert Willig argued that assigning antidumping suits to product categories more specific than the four-digit industries generally used by the authors should reveal that the negative welfare effects of antidumping actions are much more concentrated than is apparent from the paper's results, because import growth before an antidumping action is likely to be much greater and diminution of the import volume following such an action much sharper in a narrow product category than in a broader one. This concentration of welfare effects, Willig added, means that the cost per job preserved by antidumping action is greater than 
that shown by an examination at the four-digit level. He suggested that the authors attempt to use International Trade Commission (ITC) reports of individual cases to determine the more specific product categories involved in antidumping suits, conceding that this would be difficult to do because of the uneven level of detail on product information given in the reports. Willig also noted that a Federal Trade Commission staff study has estimated dumping margins, as the ITC has reported them, on a case by case basis for the last ten or fifteen years. Use of these data, he suggested, would allow the authors to replace some of their dummy variables. 


\section{References}

Abowd, John M. 1990. "The NBER Immigration, Trade, and Labor Markets Data Files." Working Paper 3351. Cambridge, Mass.: National Bureau of Economic Research. May.

Anderson, James E. 1992. "Domino Dumping, I: Competitive Exporters." American Economic Review 82 (March): 65-83.

Boltuck, Richard, and Robert E. Litan. 1991. Down in the Dumps: Administration of the Unfair Trade Laws. Brookings.

Dale, Richard. 1980. Anti-Dumping Law in a Liberal Trade Order. St. Martin's Press.

Finger, J. Michael. 1981. "The Industry-Country Incidence of 'Less than Fair Value' Cases in U.S. Import Trade." Quarterly Review of Economics and Business 21 (Summer): 260-79.

Harrison, Ann. 1991. "The New Trade Protection: Price Effects of AntiDumping and Countervailing Measures in the United States.' World Bank working paper. Washington. April.

Hartigan, James C., Sreenivas Kamma, and Philip R. Perry. 1989. "The Injury Determination Category and the Value of Relief from Dumping." Review of Economics and Statistics 71 (February): 183-86.

Herander, Mark, and J. Brad Schwartz. 1984. "An Empirical Test of the Impact of the Threat of U.S. Trade Policy: The Case of Antidumping Duties." Southern Economic Journal 51 (July): 59-79.

Hexner, Ervin. 1943. The International Steel Cartel. University of North Carolina Press.

Johnson, Norman L., and Samuel Kotz. 1969. Distributions in Statistics: Discrete Distributions. John Wiley and Sons.

Lichtenberg, Frank, and Hong Tan. 1990. "An Industry Level Analysis of Import Relief Petitions Filed by U.S. Manufacturers, 1958-85.' Unpublished manuscript.

Messerlin, Patrick A. 1989. "The EC Antidumping Regulations: A First Economic Appraisal, 1980-1985." Weltwirtschaftliches Archiv 125 (3): 56387.

1990. "Anti-Dumping Regulations or Pro-Cartel Law? The EC Chemical Cases." World Economy (December): 465-92.

Mroz, Thomas A., and David K. Guilkey. 1991. "Discrete Factor Approximations for Use in Simultaneous Equation Models with Both Continuous and Discrete Endogenous Variables." Department of Economics, University of North Carolina. November.

Prusa, Thomas J. Forthcoming. "Pricing Behavior in the Presence of Antidumping Law." Journal of Economic Integration.

. 1991. "The Selection of Antidumping Cases for ITC Determination." 
In Empirical Studies in Commercial Policy, edited by R. E. Baldwin. University of Chicago Press.

. 1992. "Why Are so Many Antidumping Petitions Withdrawn?', Journal of International Esonomics 33 (August): 1-20.

Salvatore, Dominick. 1987. "Import Penetration, Exchange Rates, and Protectionism in the United States." Journal of Policy Modeling 9 (Spring): 125-41.

Staiger, Robert W., and Frank A. Wolak. 1991. "Strategic Use of Antidumping Law to Enforce Tacit International Collusion. " Unpublished manuscript.

- 1992a. "The Effect of Antidumping Law in the Presence of Foreign Monopoly.' Journal of International Economics 32 (May): 265-87.

1992b. "Collusive Pricing with Capacity Constraints in the Presence of Demand Uncertainty." Rand Journal of Economics 23 (Summer): 20320.

1994. "The Trade Effects of Antidumping Law: Theory and Evidence." In Analytical and Negotiating Issues in the Global Trading System, edited by Alan Deardorff and Robert Stern, 231-61. University of Michigan Press. 